\title{
MERTK mutation update in inherited retinal diseases
}

\author{
Isabelle Audo ${ }^{1,2,3}$ (i) | Saddek Mohand-Said ${ }^{1,2}$ | Elise Boulanger-Scemama ${ }^{1,4}$ \\ Xavier Zanlonghi $^{5}$ | Christel Condroyer ${ }^{1}$ | Vanessa Démontant ${ }^{1}$ | Fiona Boyard $^{1}$ | \\ Aline Antonio $^{1}$ | Cécile Méjécase ${ }^{1}$ (i) | Said El Shamieh ${ }^{1,6}$ (iD | \\ José-Alain Sahel ${ }^{1,2,3,4,7,8}$ (iD) | Christina Zeitz ${ }^{1}$ (D)
}

${ }^{1}$ Sorbonne Université, INSERM, CNRS, Institut de la Vision, Paris, France
${ }^{2}$ CHNO des Quinze-Vingts, DHU Sight Restore, INSERM-DGOS CIC1423, Paris, France
${ }^{3}$ University College London Institute of Ophthalmology, London, UK
${ }^{4}$ Fondation Ophtalmologique Adolphe de Rothschild, Paris, France
${ }^{5}$ Clinique Pluridisciplinaire Jules Verne, Nantes, France
${ }^{6}$ Department of Medical Laboratory Technology, Faculty of Health Sciences, Beirut Arab University, Beirut, Lebanon
${ }^{7}$ Académie des Sciences-Institut de France, Paris, France
${ }^{8}$ Department of Ophthalmology, University of Pittsburgh Medical School, Pittsburgh, Pennsylvania

Correspondence

Isabelle Audo, Department of Genetics, Institut de la Vision, 17, rue Moreau, 75012 Paris, France. Email: isabelle.audo@inserm.fr

Christina Zeitz, Department of Genetics, Institut de la Vision, 17, rue Moreau, 75012 Paris, France. Email:christina.zeitz@inserm.fr

Funding information

Contract grant sponsors: Fondation Voir et Entendre; LABEX LIFESENSES (ANR-10-

LABX-65); Agence Nationale de la Recherche within the Investissements d'Avenir program (ANR-11-IDEX-0004-0); Foundation Fighting Blindness center grant (C-C-CL-0912-0600INSERM01, GE-0912-0601-INSERM02); Prix de la Fondation de l'CEil; Ministère de I'Enseignement Supérieur et de la Recherche (MESR).

Communicated by Jürgen Horst

\begin{abstract}
MER tyrosine kinase (MERTK) encodes a surface receptor localized at the apical membrane of the retinal pigment epithelium. It plays a critical role in photoreceptor outer segment internalization prior to phagocytosis. Mutations in MERTK have been associated with severe autosomal recessive retinal dystrophies in the RCS rat and in humans. We present here a comprehensive review of all reported MERTK disease causing variants with the associated phenotype. In addition, we provide further data and insights of a large cohort of 1,195 inherited retinal dystrophies (IRD) index cases applying state-of-the-art genotyping techniques and summarize current knowledge. A total of 79 variants have now been identified underlying rod-cone dystrophy and cone-rod dystrophy including 11 novel variants reported here. The mutation spectrum in MERTK includes 33 missense, 12 nonsense, 12 splice defects, 12 small deletions, 2 small insertion-deletions, 3 small duplications, and 2 exonic and 3 gross deletions. Altogether, mutations in MERTK account for $\sim 2 \%$ of IRD cases with a severe retinal phenotype. These data are important for current and future therapeutic trials including gene replacement therapy or cell-based therapy.
\end{abstract}

\section{KEYWORDS}

inherited retinal dystrophy, MERTK, mutation spectrum, mutation prevalence

\section{1 | BACKGROUND}

Inherited retinal diseases (IRD) are a clinically and genetically heterogeneous group of disorders characterized by progressive photoreceptor degeneration (Hartong, Berson, \& Dryja, 2006). Its prevalence is estimated from one out of 3,500 to one out of 5,000 worldwide with variable ages of onset and degrees of severity. So far, close to 250 genes have been implicated in cases of IRD (https://sph.uth.edu/retnet/) following all modes of Mendelian or mitochondrial inheritance with rare cases of digenism. Most of these genes encode proteins involved in various cellular functions essential for photoreceptor or retinal pigment epithelium (RPE) homeostasis (Wright, Chakarova, Abd El-Aziz, \& Bhattacharya, 2010). The most common form of IRD is rodcone dystrophy (RCD), also known as retinitis pigmentosa (RP) (MIM\# 268000), which manifests with night blindness, progressive visual field constriction and possible loss of central vision due to gradual dysfunction, and loss of rod photoreceptors followed by cone photoreceptors. On the other hand, cone and cone-rod dystrophies (CCRD) (e.g., MIM\# 602093, 304020, and 120970) start by a decreased vision, photophobia with possible secondary night blindness, and peripheral visual field abnormalities leading to blindness. Of note, the distinction between RCD and CCRD is sometime clinically difficult, especially 
in advanced or severe cases, and there are overlapping genetic mechanisms, mutations for some genes leading to both phenotypes (Boulanger-Scemama et al., 2015). There is currently no cure for IRD and most of them result in severe visual impairment or blindness with however promising clinical trials or therapeutic perspectives advocating for a better clinical and genetic characterization (Thompson et al., 2015).

MERTK (MER proto-oncogene, tyrosine kinase) (MIM\# 604705) is one of the mutated genes in IRD. It is localized in 2q14.1 (Weier, Fung, \& Lersch, 1999) and comprises 19 exons. It encodes the tyrosine-protein kinase Mer, a 999-amino-acid transmembrane protein (Uniprot \# Q12866) belonging to the TAM (TYRO3/AXL/MER) receptor kinase family, a family of homeostatic regulators for the mature immune, reproductive, hematopoietic, vascular, and nervous systems mainly through its phagocytic function of apoptotic cells (Lemke, 2013). MERTK is highly expressed in monocyte/macrophages, ovary, prostate, testis, lung, and kidney as well as in epithelial cells including the RPE. In the RPE, it plays a critical role for shed photoreceptor outer segment (POS) engulfment prior to phagocytosis, a circadian process essential for photoreceptor homeostasis (Feng, Yasumura, Matthes, LaVail, \& Vollrath, 2002; Kevany \& Palczewski, 2010). MERTK functional domains, common to the TAM receptors, include two immunoglobulin-like-C2 (Ig-like C2 type 1 from amino acid (aa) residue 81 to 186 and Ig-like C2 type 2 aa residue 197 to 273) and two fibronectin type III (FN-III from aa residue 286 to 381 and 386 to 484 ) domains in its extracellular portion and an intracellular region with a highly conserved kinase domain (aa residue 587 to 858) including the $\mathrm{KW}(\mathrm{I} / \mathrm{L}) \mathrm{A}(\mathrm{I} / \mathrm{L}) \mathrm{ES}$ motif characteristic of the TAM receptors (Figure 1) (Strick \& Vollrath, 2010). In addition, the kinase domain contains three autophosphorylation sites (Tyr-749, Tyr-753, Tyr-754), which are critical for its full activity (Ling, Templeton, \& Kung, 1996). MERTK exists as a membrane-bound receptor and as a soluble form (Sather et al., 2007) through its cleavage at proline 485 by ADAM17 (MIM\# 603639), at least in murine macrophages and RPE cells (Law et al., 2015; Thorp et al., 2011). This soluble form would act as a negative feedback loop limiting POS binding to RPE cell surface prior to phagocytosis (Nandrot et al., 2012). Phagocytosis of POS is a complex process which is now at least partially understood (Mazzoni, Safa, \& Finnemann, 2014). The exposure of phosphatidyl serines (PS) at the surface of POS is the triggering stimulus. On one side, PS are recognized by the complex formed by the milk fat globule-EGF-factor 8 (MFG-E8) (MIM\# 602281) bound to $\alpha v \beta 5$ integrin (MIM\# 193210, MIM\# 147561), CD36 (MIM\# 173510) and possibly other unknown partners. MFG-E8/ $\alpha \vee \beta 5$ recognition leads to the protein tyrosine kinase 2 (MIM\# 600758) (previously known as focal adhesion kinase) activation at the apical membrane of the RPE and to its autophosphorylation. This process is important for MERTK activation (Nandrot et al., 2004). On the other side, MERTK indirectly interacts with PS through its ligands, Gas6/Protein S (MIM\# 600441, MIM\# 176880) which results in MERTK autophosphorylation at the three sites abovementioned and in cellular actin remodeling, through myosin light chain 2 (MIM\# 160781). MERTK is then involved in POS engulfment through an interaction with its ligands. POS are subsequently internalized and degraded (reviewed in Kevany \& Palczewski, 2010).
MERTK was first associated with retinal degeneration after the identification of a deletion causing the naturally occurring autosomal recessive (ar) retinal degeneration of the Royal College of Surgeon (RCS) rat (D'Cruz et al., 2000; Nandrot et al., 2000), a retinal dystrophy model secondary to a phagocytic defect of the RPE (Bok \& Hall, 1971; Dowling \& Sidman, 1962; Edwards \& Szamier, 1977; Herron, Riegel, Myers, \& Rubin, 1969; LaVail \& Battelle, 1975; Li \& Turner, 1988). Shortly after this discovery, mutations in MERTK were identified in patients with ar RP (Gal et al., 2000). More recently, an overexpression of MERTK was found in a canine progressive retinal atrophy, from a Swedish Vallhund breed, suggesting a gain of function mutation which still needs to be molecularly characterized (Ahonen et al., 2014). An ongoing clinical trial with gene augmentation in patients with IRD linked to MERTK mutations in Saudi Arabia (NCT01482195) (Ghazi et al., 2016) as well as interesting perspectives in cell therapy (Zarbin, 2016) are an incentive to conduct comprehensive studies to prepare patients for these therapies. In the present manuscript, we provide a comprehensive review on reported variants in MERTK associated with IRD, add further data generated by the screening of a large French cohort of more than 1000 IRD index cases, deliver new information on prevalence and discuss phenotype-genotype correlations.

\section{2 | MATERIAL AND METHODS}

\section{1 | Literature search}

Literature search was performed on Pubmed, with a last check on March 12th, 2018, in order to collect all reported variants on MERTK (NM_006343.2) in association with IRD. Additional databases were queried such as The Human Gene Mutation Database (HGMD ${ }^{\circledR}$ Professional 2017.4, last queried on March 12th, 2018), Leiden Open Variation Database (LOVD V.3.0), last queried on March 12th, 2018, Retina International Mutation Database (https://www. retina-international.org/files/sci-news/mertkmut.htm, last updated in March 2004). For each of the reported variants, we collected information on phenotype/genotype correlation, familial segregation and documented minor allele frequency (MAF) as well as assessed functional impact through in silico pathogenic predictions tools.

\section{2 | Novel MERTK variants}

In addition to the comprehensive literature search, we analyzed a large French cohort of 1,195 unrelated subjects with IRD. Each patient underwent a full ophthalmic examination as described elsewhere (Audo et al., 2010). After this clinical evaluation, patients and family members were asked to donate a blood sample for DNA extraction and further genetic studies. Written informed consent was obtained from each subject after explanation of the study and its potential outcomes. The study protocol adhered to the tenets of the Declaration of Helsinki and was approved by the local ethics committee (CPP, Comité de Protection des Personnes Ile de France V, project number 06693, N EUDRACT 2006-A00347-44).

The DNA of patients with a presumed diagnosis of autosomal recessive RCD and cone-rod dystrophy (CRD) was assessed. Microarray 


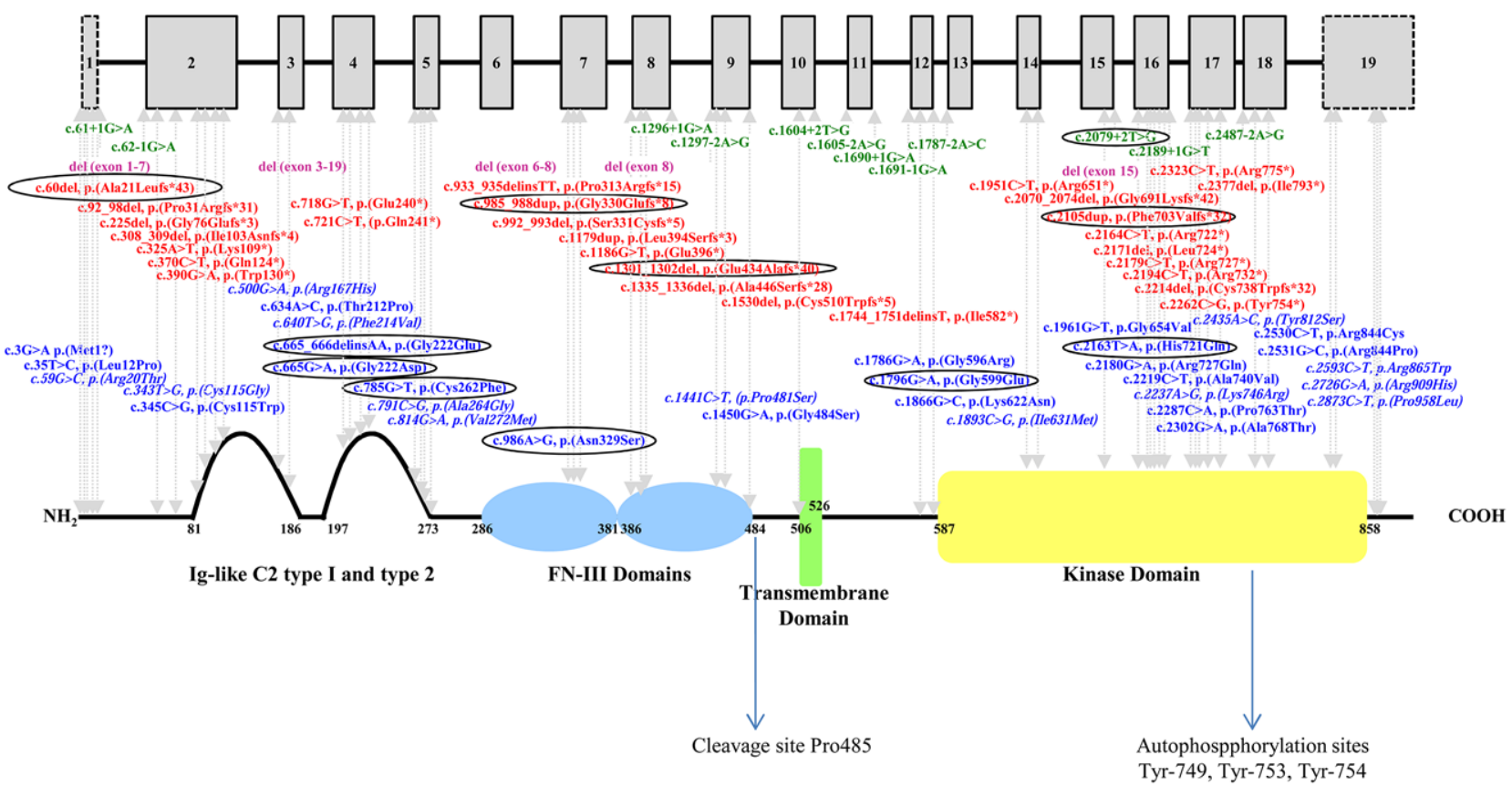

FIGURE 1 Distribution of the 68 MERTK variants reported in the literature (sources: pubmed search up to the March 12, 2018) and the 11 novel variants identified by our group in the gene and protein. Nucleotide numbering is based on cDNA sequence of MERTK (RefSeq NM_006343.2) where A of the ATG initiation codon is 1 . The nonsense and frameshift mutations appear in red, gross deletions appear in purple, missense variants in blue and the splice site change in green. Novel variants are circled in black. The protein is a transmembrane protein and its structure includes: in the extracellular portion, two immunoglobulin-like-C2 (Ig-like C2 type 1 and type 2) from amino acid (aa) residue 81 to 186 and residue 197 to 273 , respectively, two fibronectin type III domains (FN-III in blue from aa residue 286 to 381 and 386 to 484 ) and an intracellular region with a highly conserved kinase domain (in yellow from aa residue 587 to 858 ). The respective residues are written below the protein schematic

analysis on a commercial chip (ASPER Ophthalmics, Tartu, Estonia) (Koenekoop, Lopez, den Hollander, Allikmets, \& Cremers, 2007) was initially applied to 186 index patients with IRD. Samples with no identified pathogenic variant as well as additional new index cases were subsequently investigated through a targeted nextgeneration sequencing (NGS) as described previously (Audo et al., 2012; Boulanger-Scemama et al., 2015). Guidelines from the American College of Medical Genetics and Genomics were used for variant classification (Richards et al., 2015). Functional impact was assessed using in silico prediction tools (i.e. Align GVGD (https://agvgd.hci. utah.edu/agvgd_input.php) (Tavtigian et al., 2006), Mutation Taster (https://www.mutationtaster.org/) (Schwarz, Cooper, Schuelke, \& Seelow, 2014), Sorting Intolerant From Tolerant SIFT (https:// sift.jcvi.org/) (Kumar, Henikoff, \& Ng, 2009), Polymorphism Phenotyping v2 Polyphen-2 (https://genetics.bwh.harvard.edu/pph2/) (Adzhubei et al., 2010), Splice Site Prediction by Neural Network, NNSPLICE, https://www.fruitfly.org/seq_tools/splice.html, (Reese, Eeckman, Kulp, \& Haussler, 1997); Human Splicing Finder v.2.4.1, HSF, https://www.umd.be/HSF/\#, (Desmet et al., 2009) and evolutionary conservation (UCSC Genome Browser (https://genome.ucsc.edu/index.html; Human GRCh37/hg19 Assembly)). Only rare variants with a MAF below or equal to 0.005 in the Exome Aggregation consortium (ExAC, https://exac. broadinstitute.org/) and genome Aggregation Database (gnomAD, https://gnomad.broadinstitute.org/) were considered. Each predicted pathogenic variant was confirmed by Sanger sequencing of the respective target (RefSeq NM_006343.2, primer sequences available upon request). NGS data were also analyzed to detect Copy Number Variation and cases with large deletions were confirmed applying Multiplex Ligation-dependent Probe Amplification as performed before (Boulanger-Scemama et al., 2015). Familial segregation analysis with Sanger sequencing of the PCR amplified fragments including the identified putative pathogenic variant(s) was performed when possible.

\section{3 | MERTK VARIANTS UNDERLYING IRD}

A total of 68 genetic changes were found in the literature underlying IRD. These variants span the entire gene and therefore impact on all functional domains (Figure 1 and Table 1). In addition, the screening of a large cohort of IRD followed at our center (1,095 RCD and 100 CRD) identified 11 novel changes (Figure 1, Table 1, Supp Figure S1, and Supp. Table S1). Altogether, the mutation spectrum includes 33 missense mutations among which 4 may affect splicing and 13 are of questionable pathogenicity (based on allele frequency $>0.005$, functional assays or only found at the single heterozygous state, presented in italic in Table 1), 12 nonsense mutations, 12 splice site defects, 12 small deletions, 2 small insertion-deletions, 3 small duplication, 2 large exonic deletions, and 3 gross deletions. The screening of our large IRD cohort identified a total of 20 distinct mutations among which 11 are novel. The mutation spectrum in our cohort includes 3 small deletions, 2 small duplications, 1 large exonic deletion, 2 splice defects, 9 missense and 3 nonsense changes. All the mutations were 


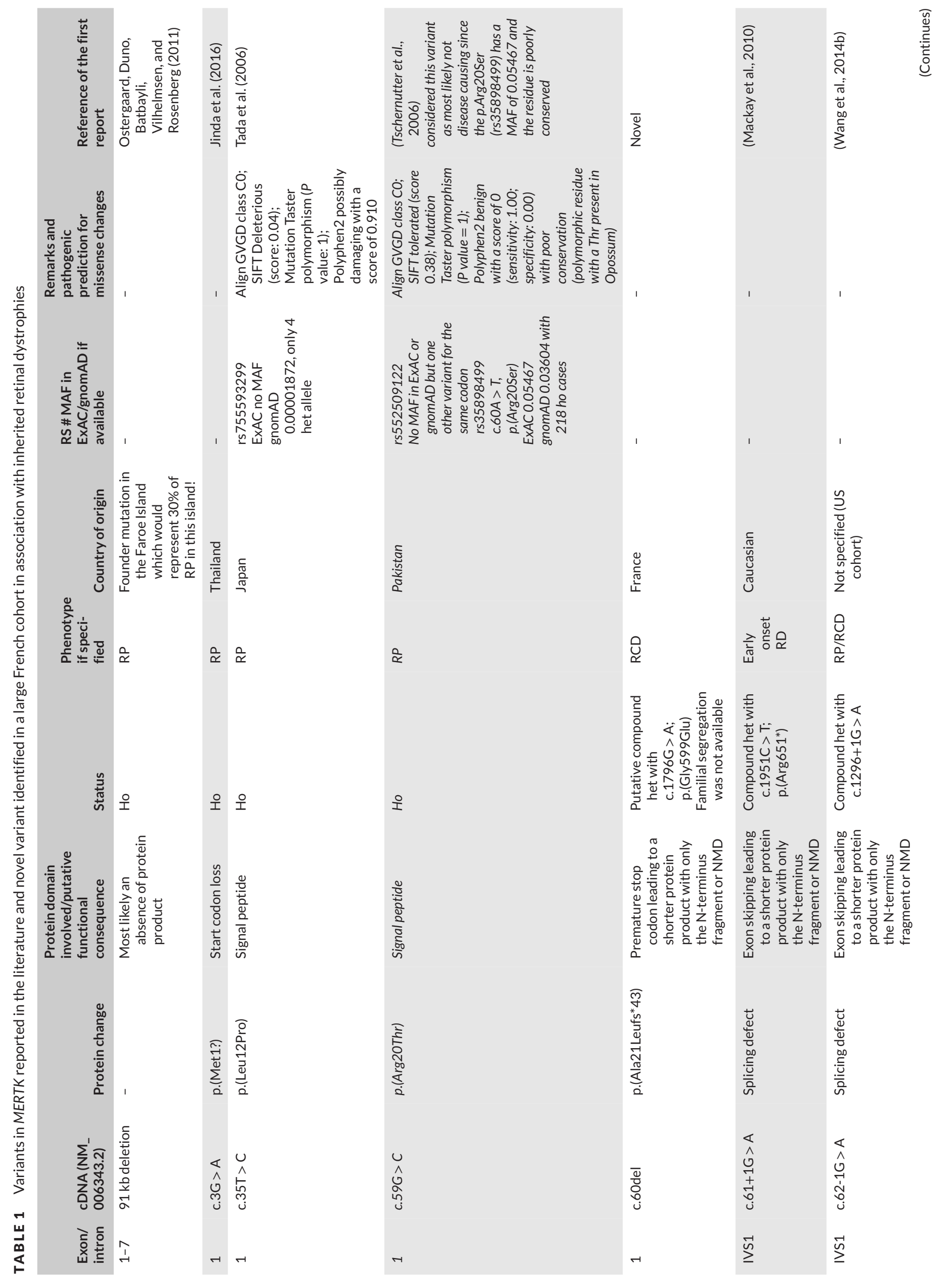




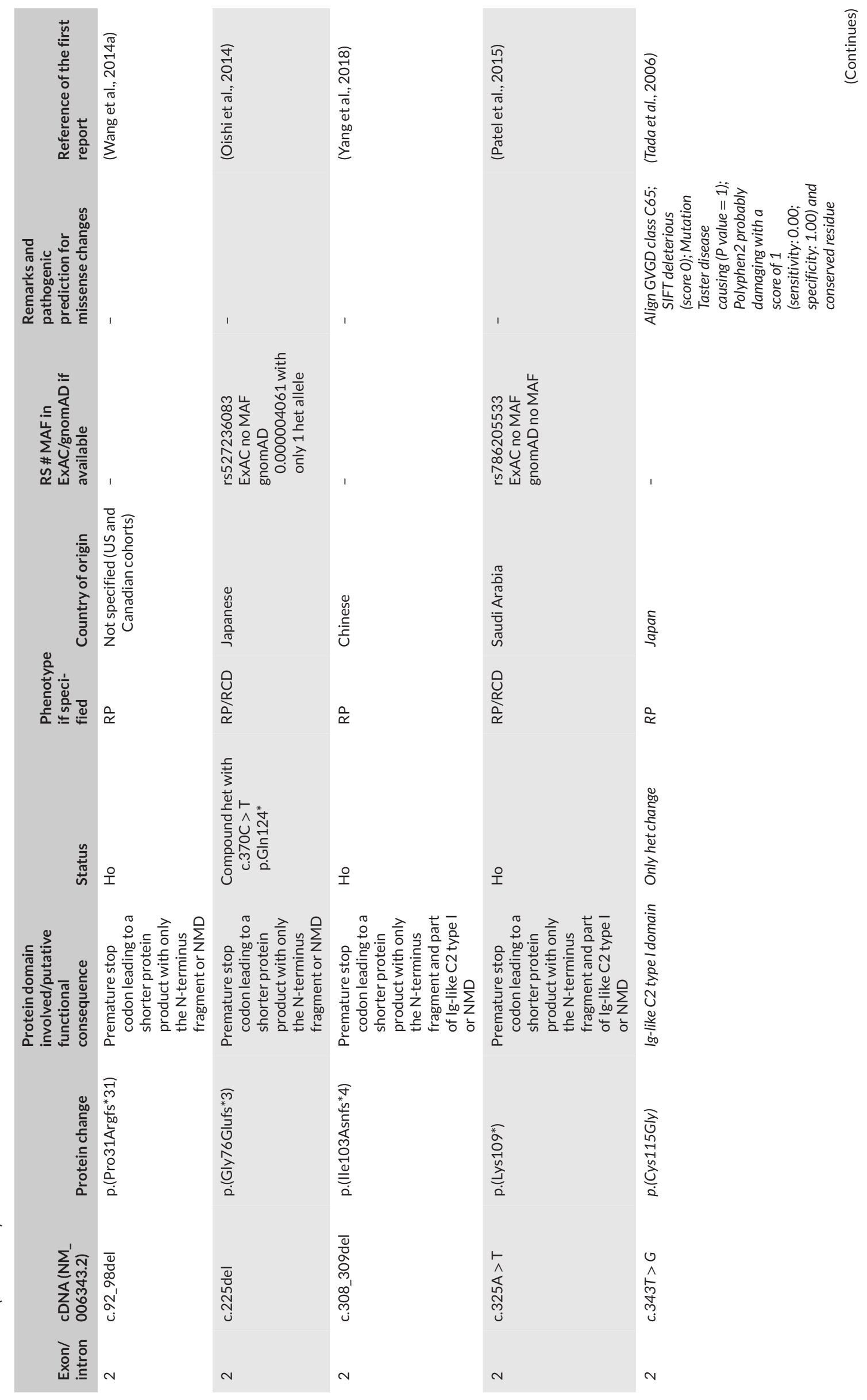




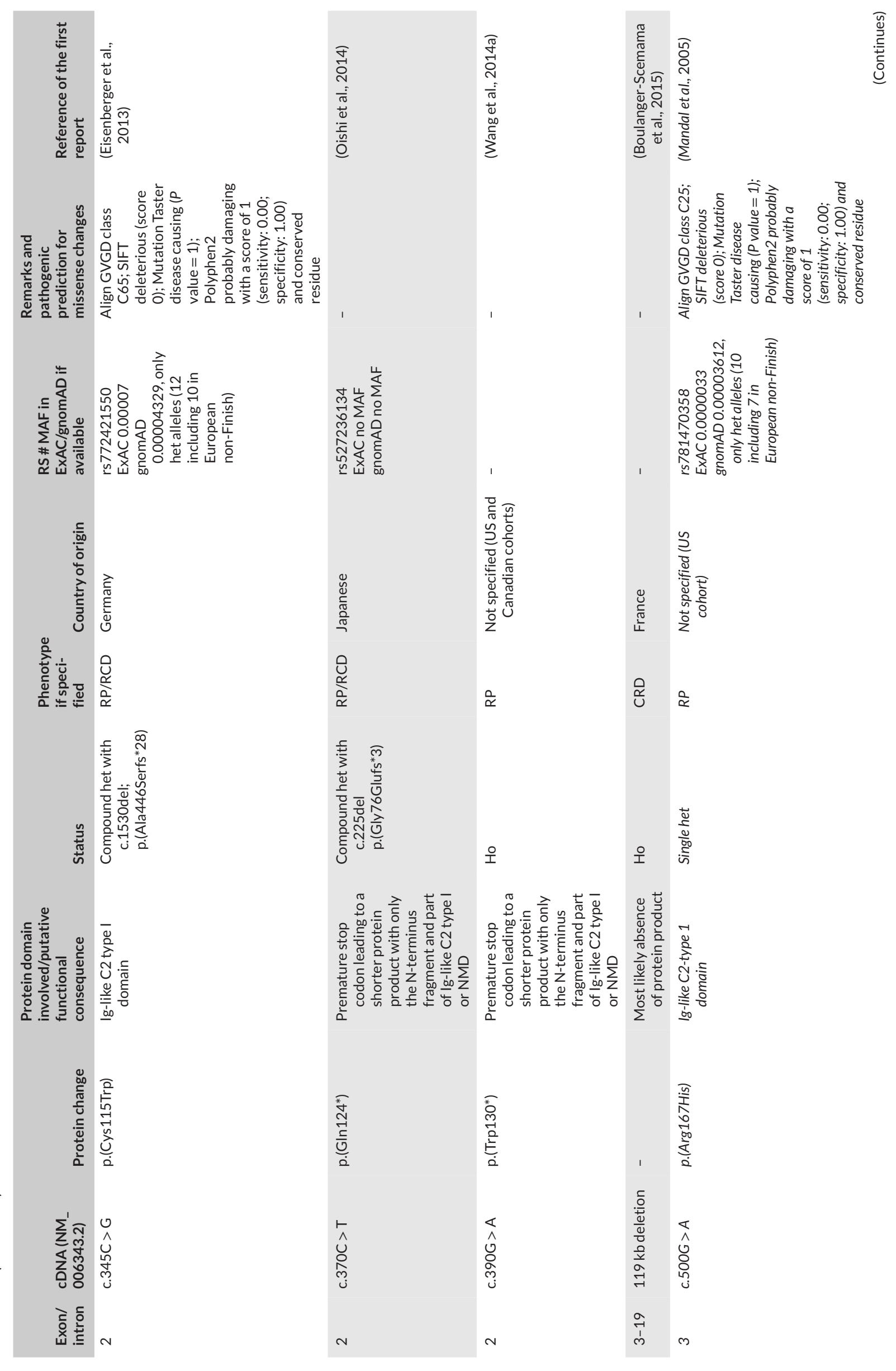



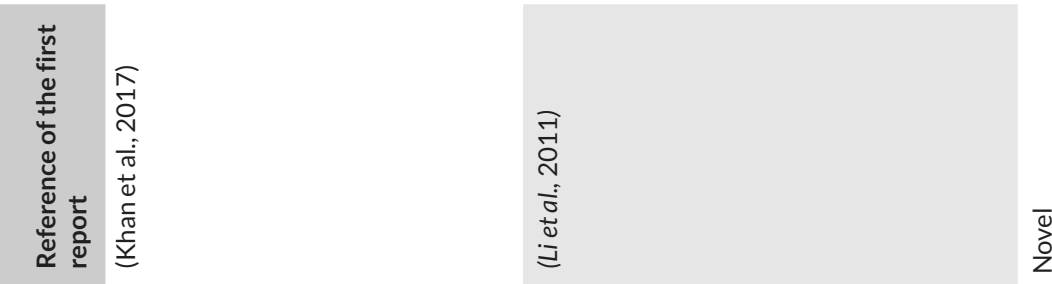

高

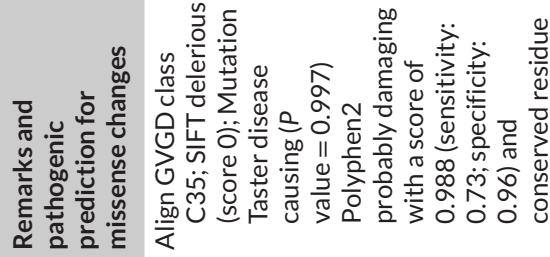
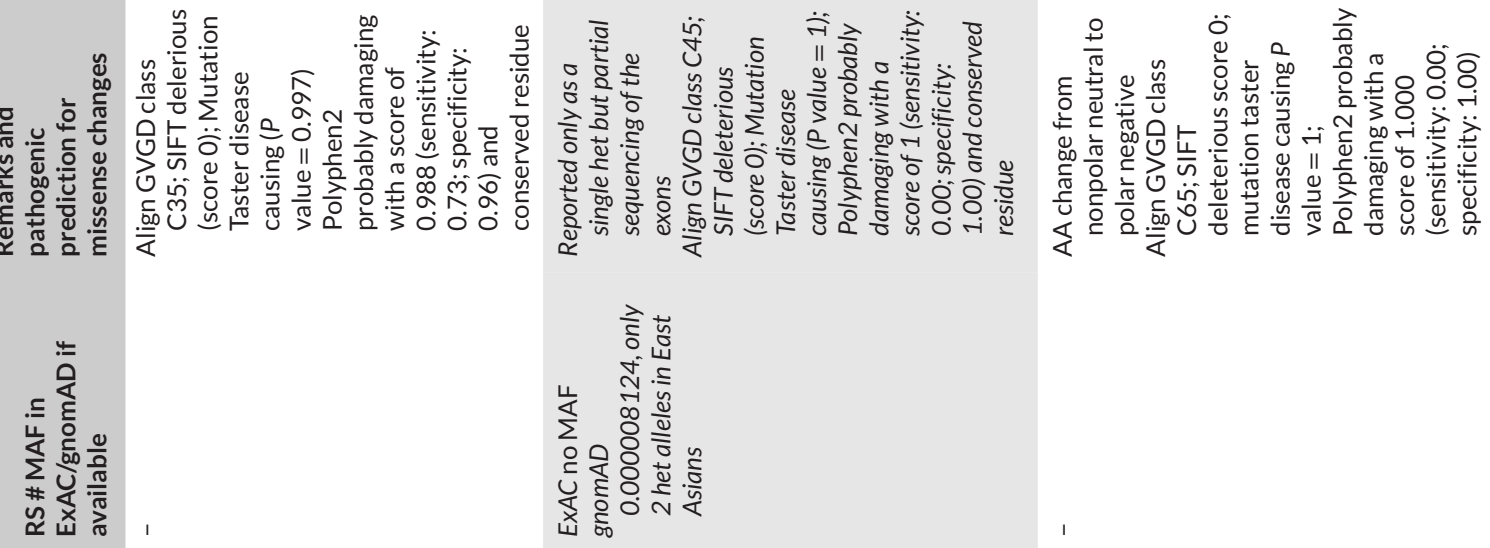

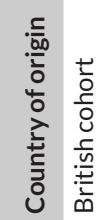

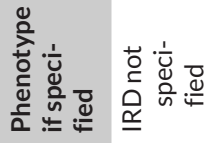

ปั

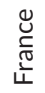

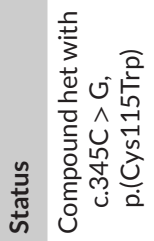

త

ษั
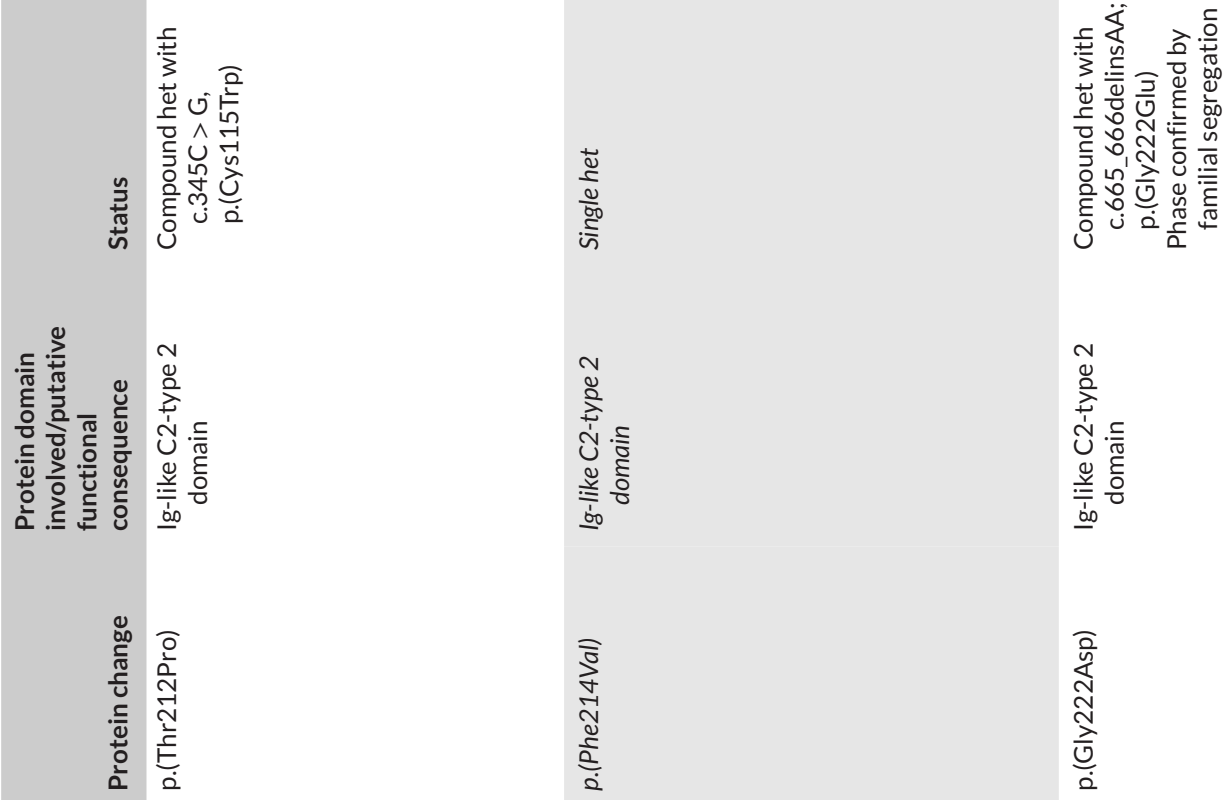

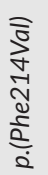

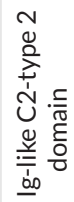

$\sqrt{1}$

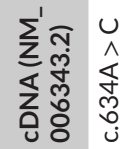

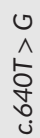

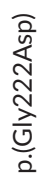

占热就

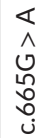




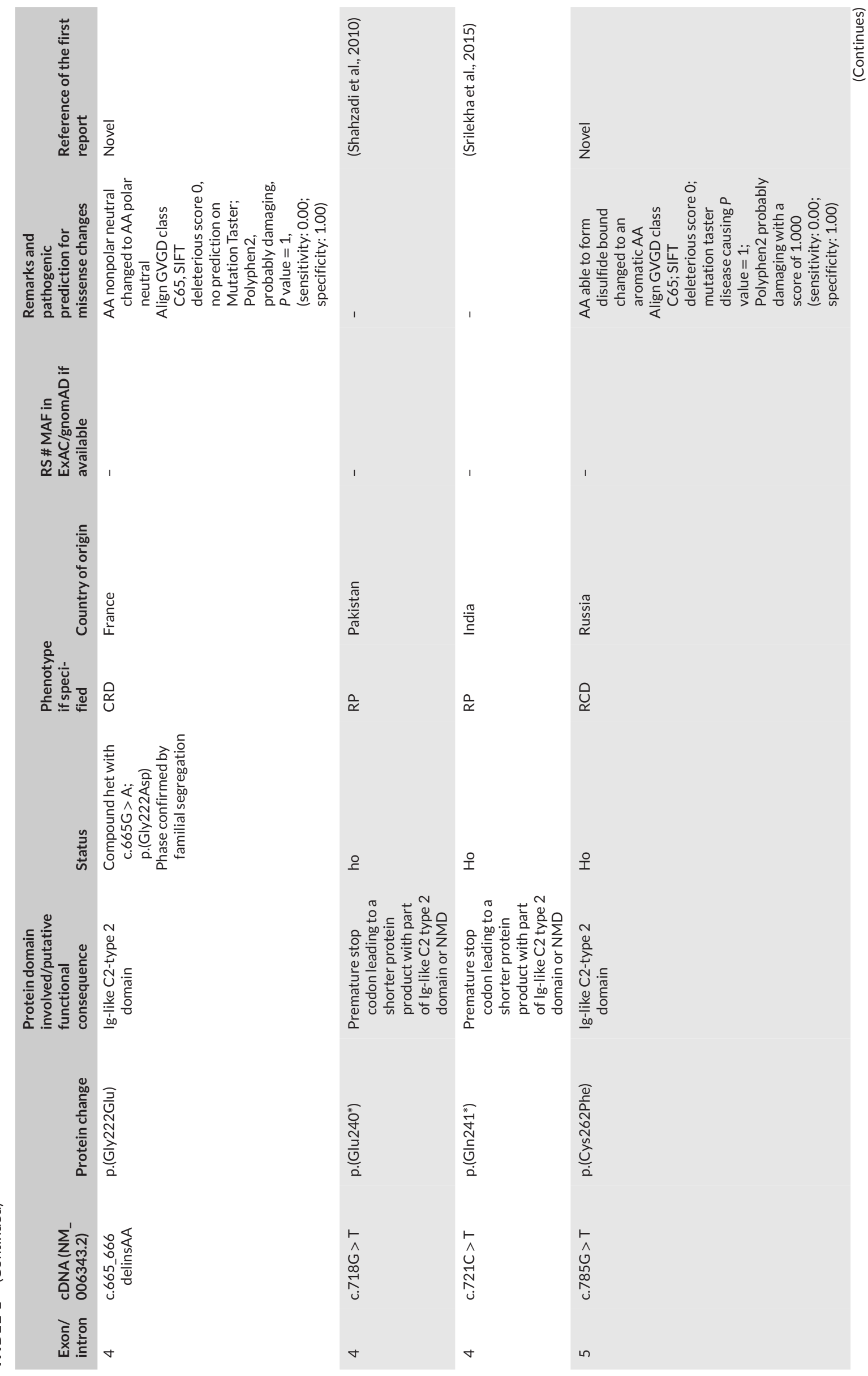




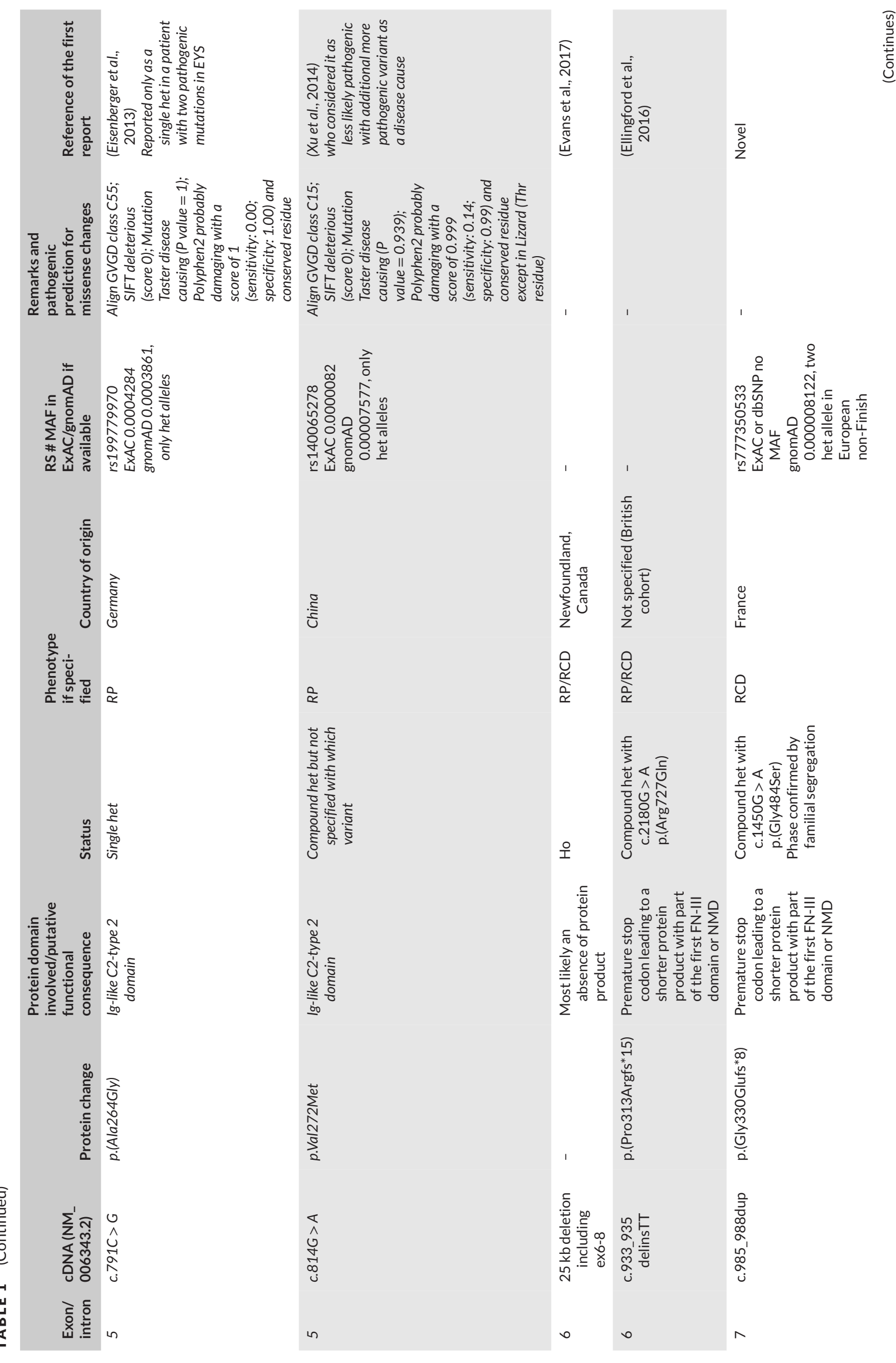




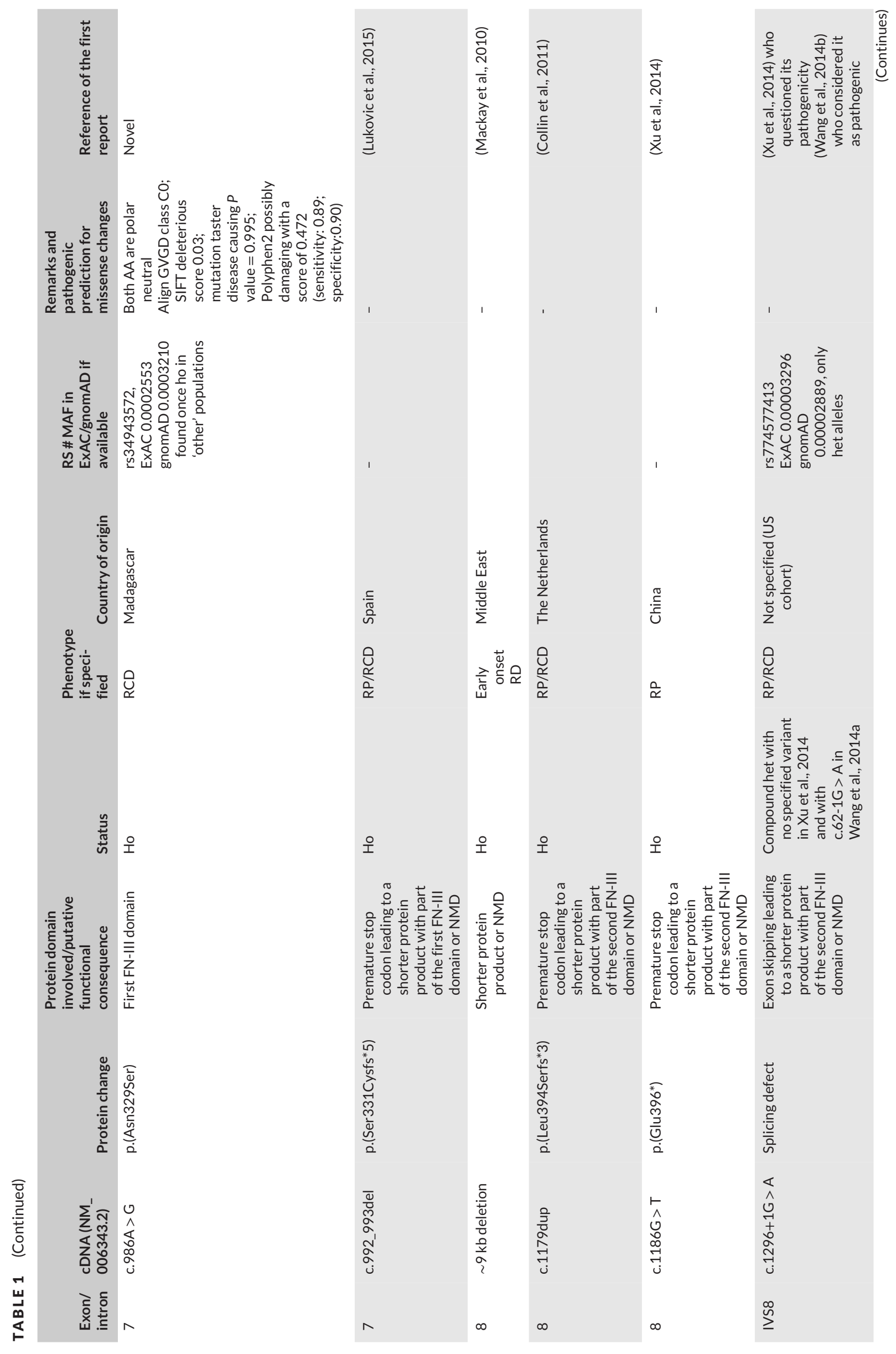




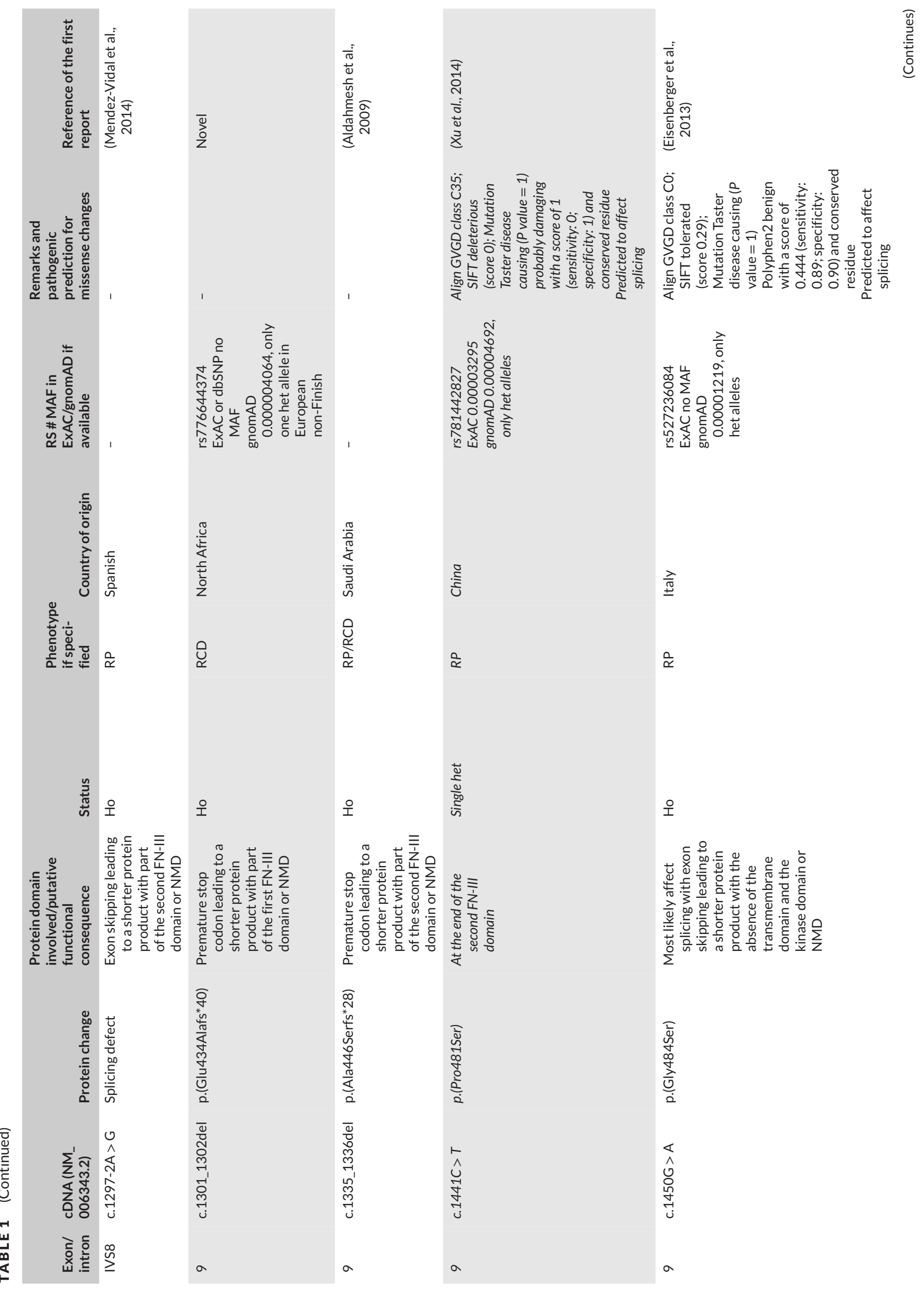




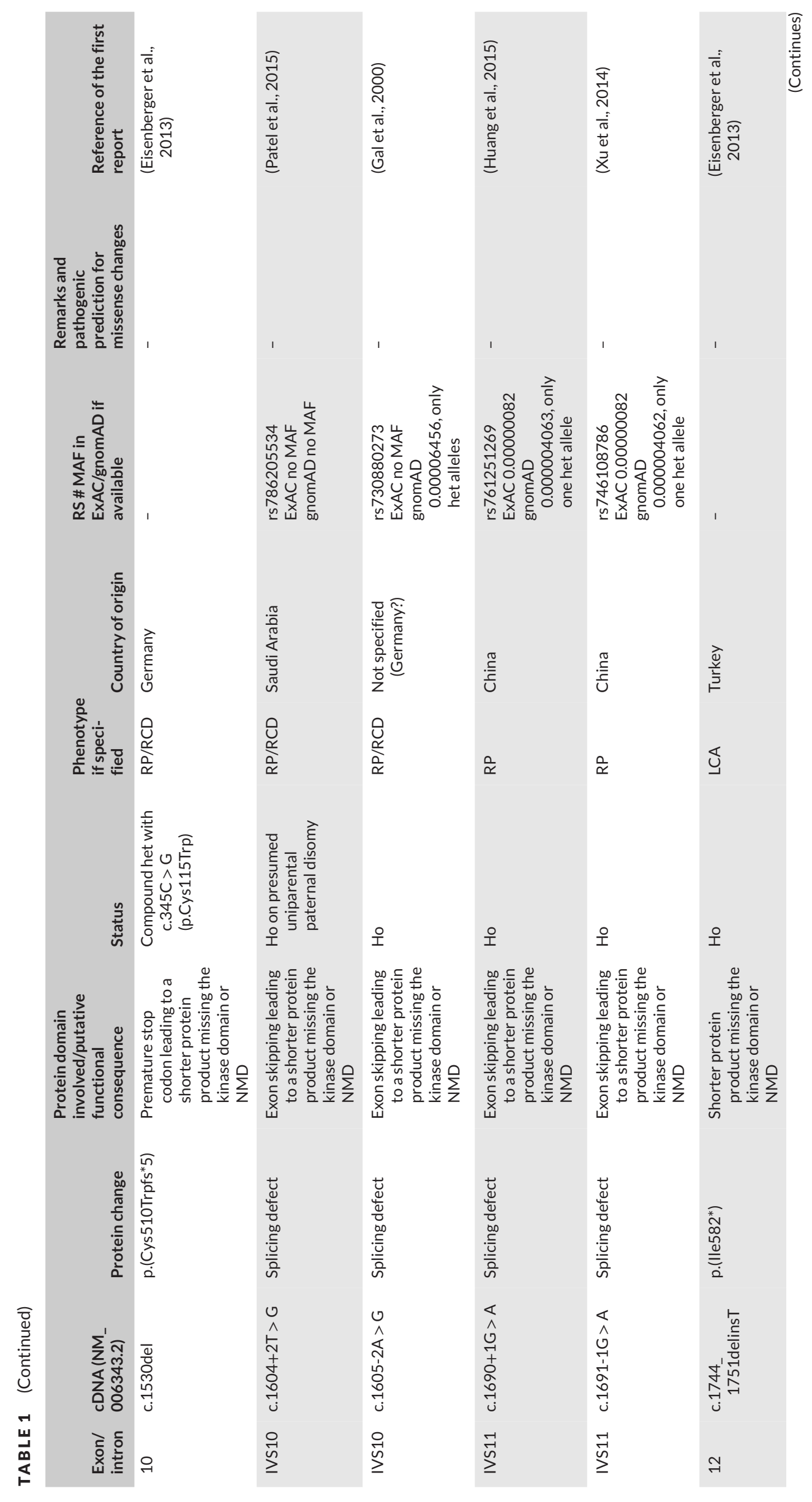



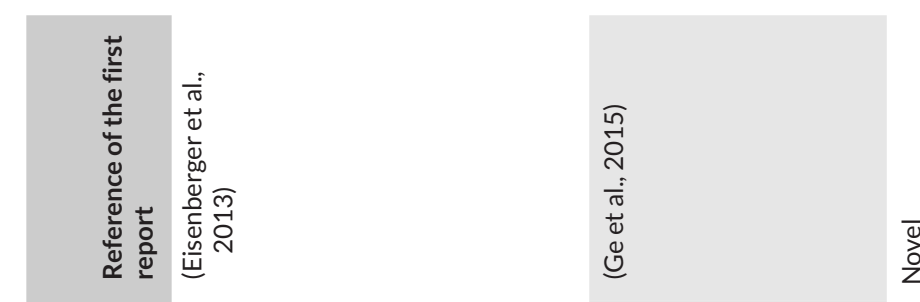

I

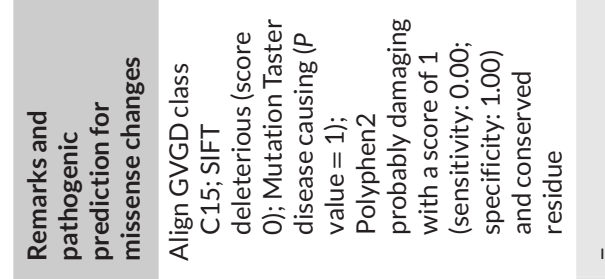

ò
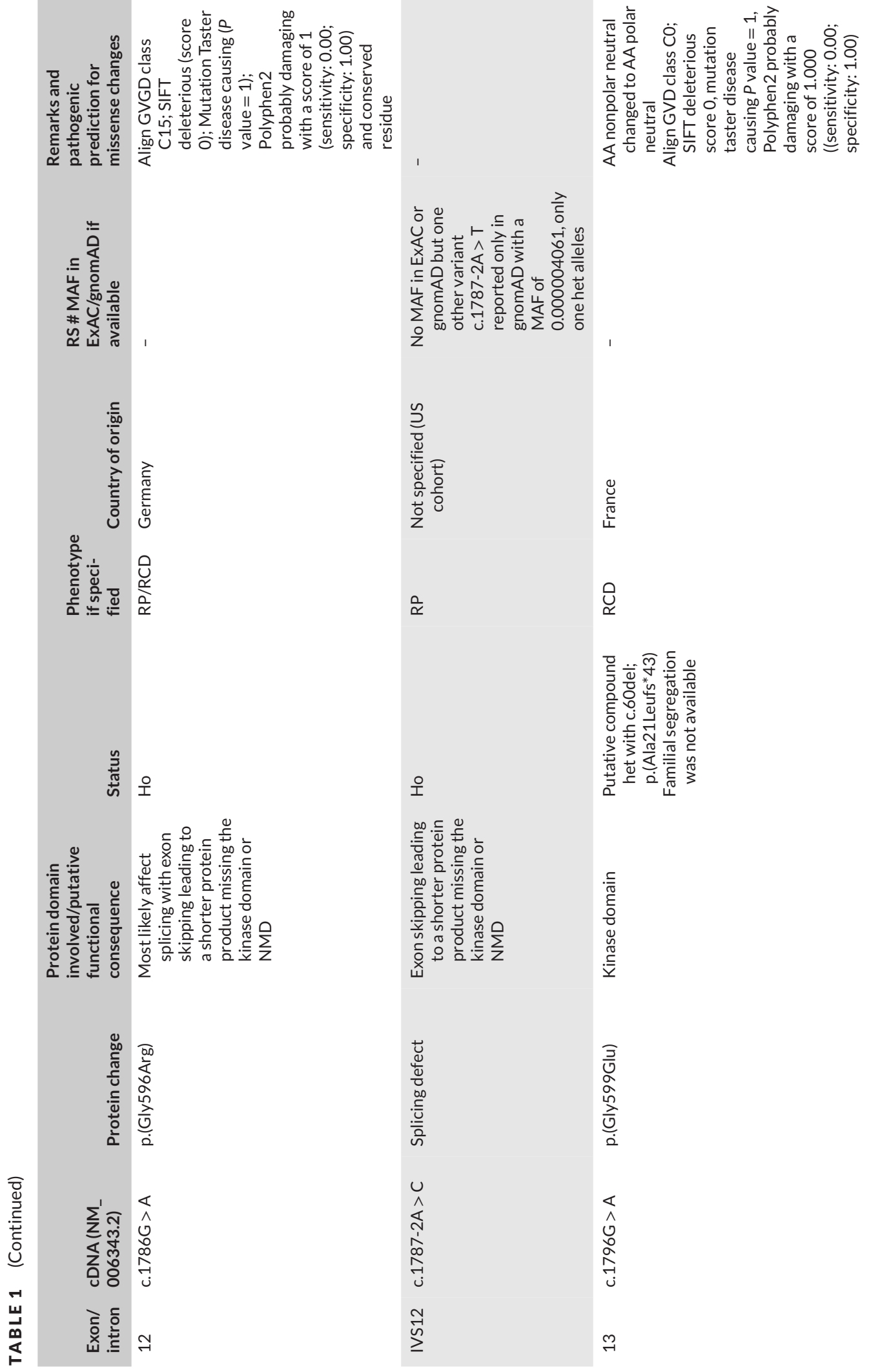


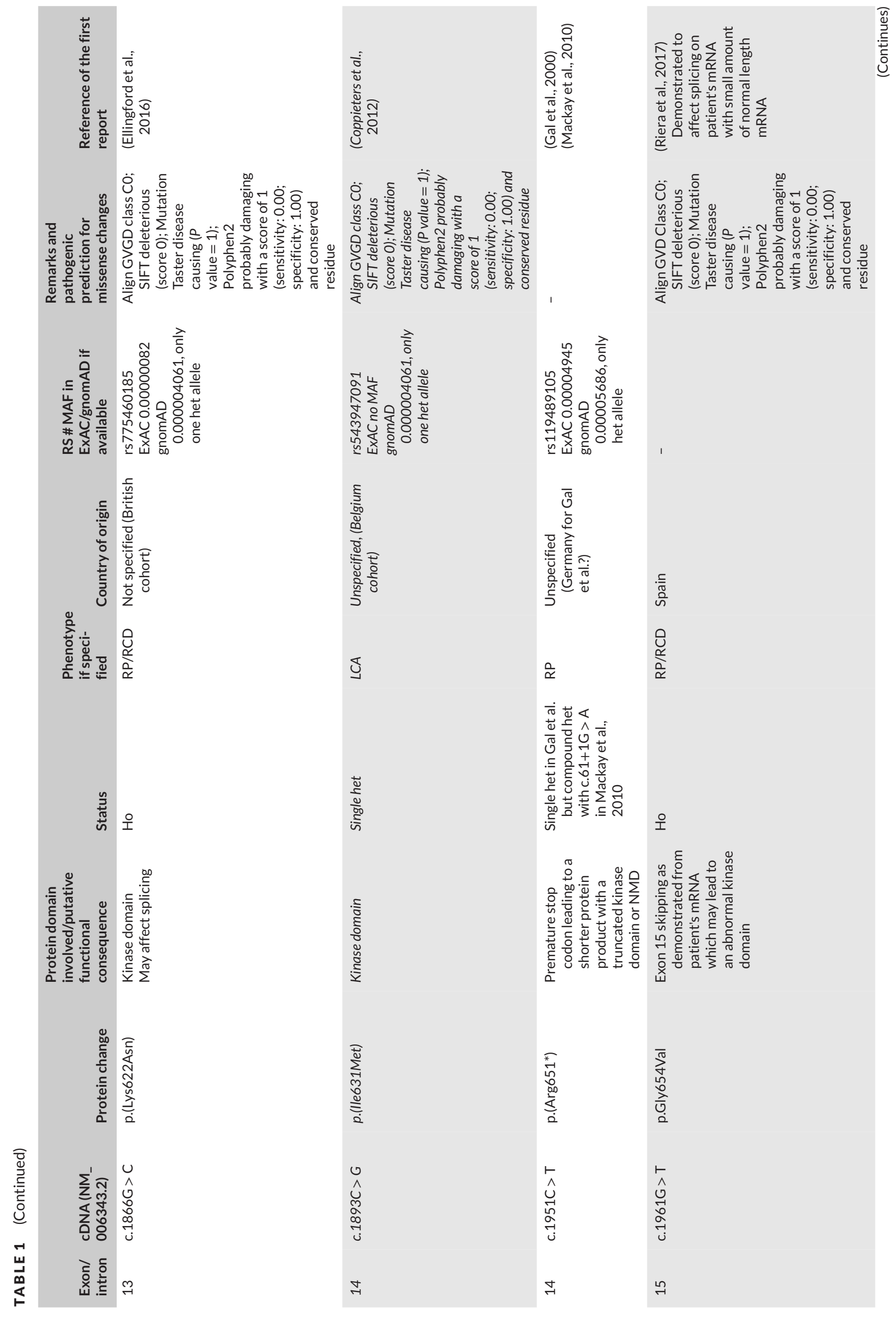



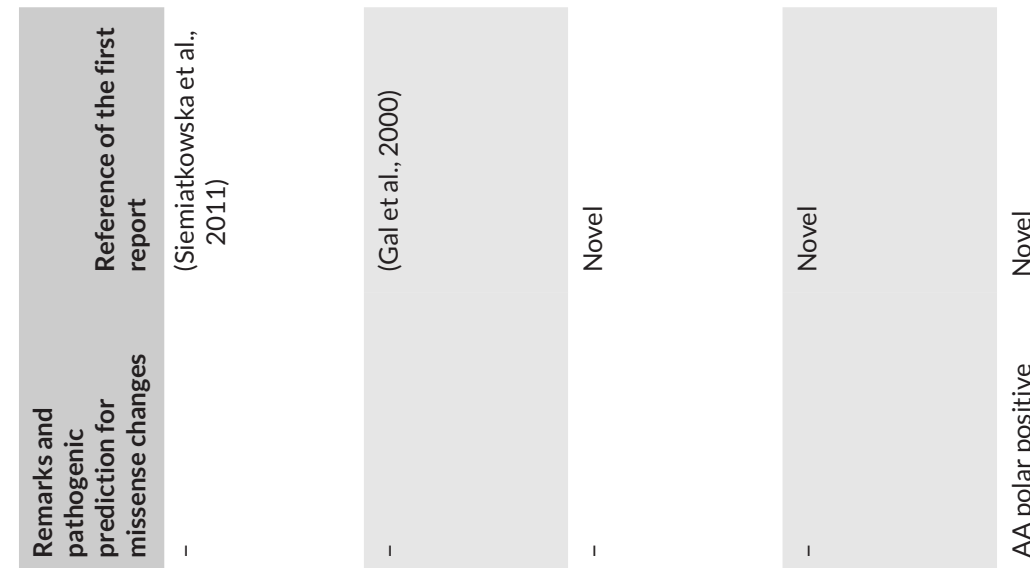

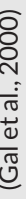

गे
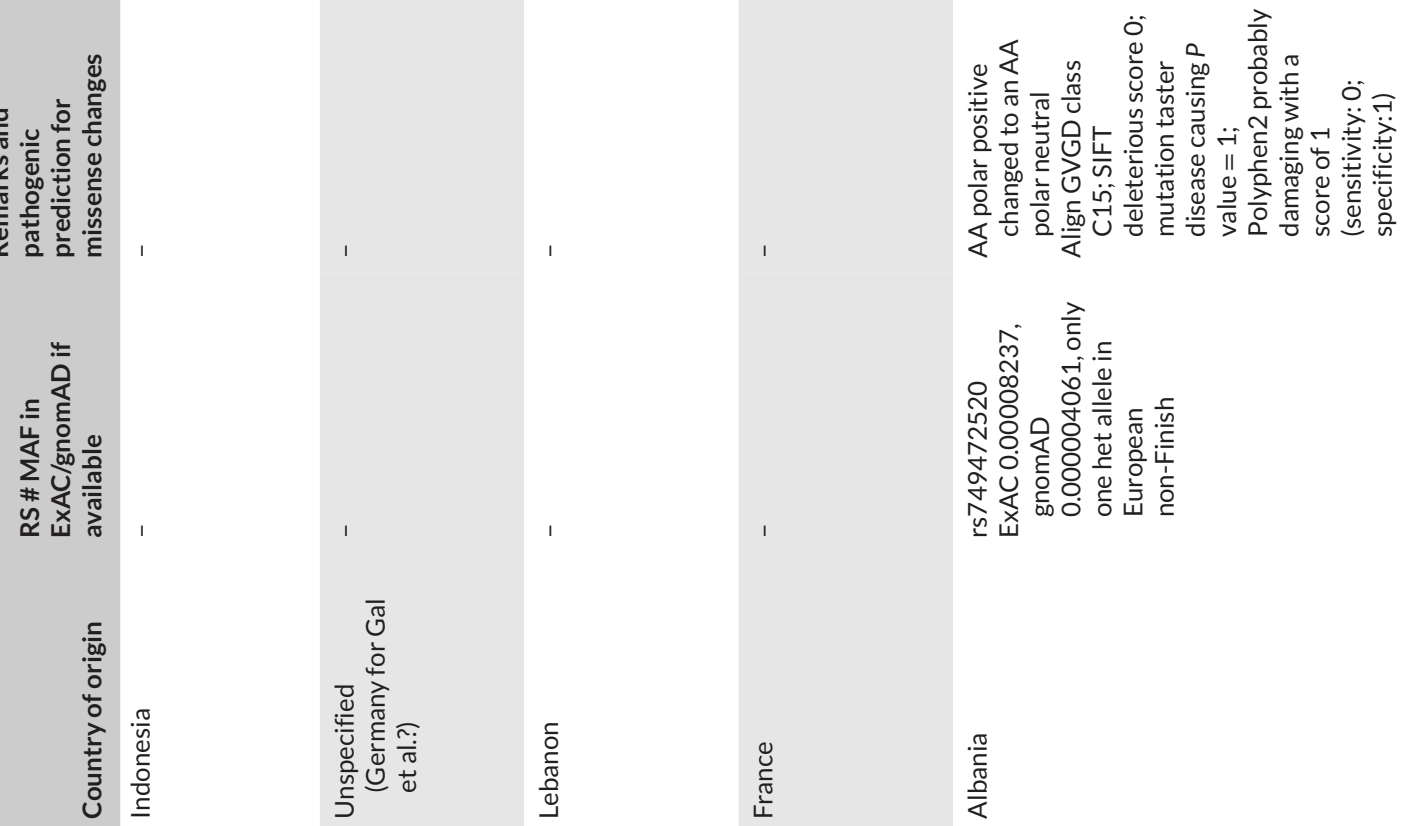

京

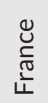

高

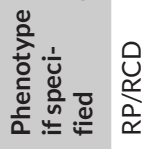

$\underset{\Upsilon}{\Upsilon}$

ญ

U.

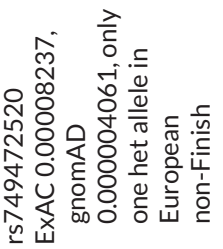

苟 우
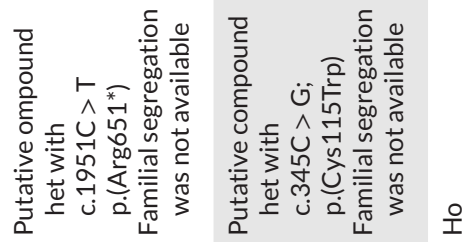

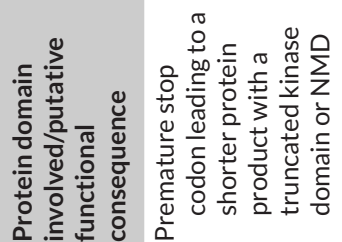

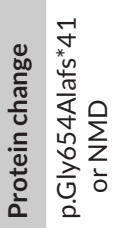

오

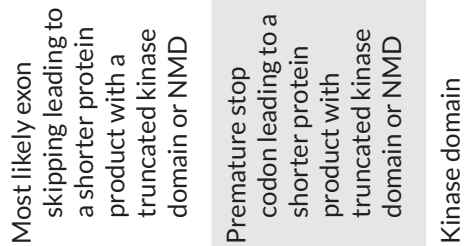

高
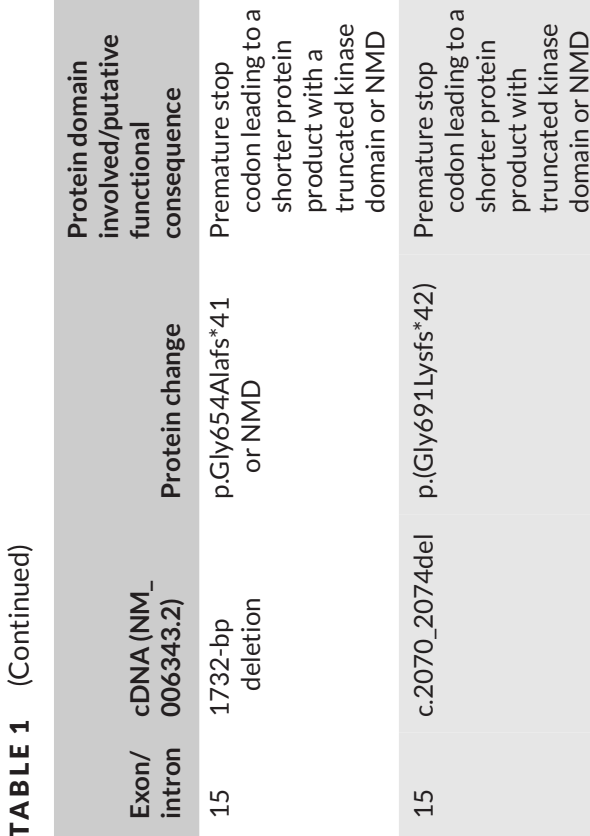

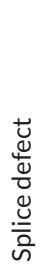

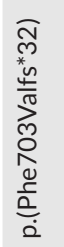

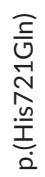

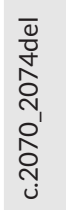

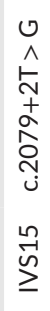

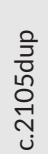

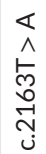

$\stackrel{n}{\rightarrow}$

$\stackrel{1}{-1}$ 


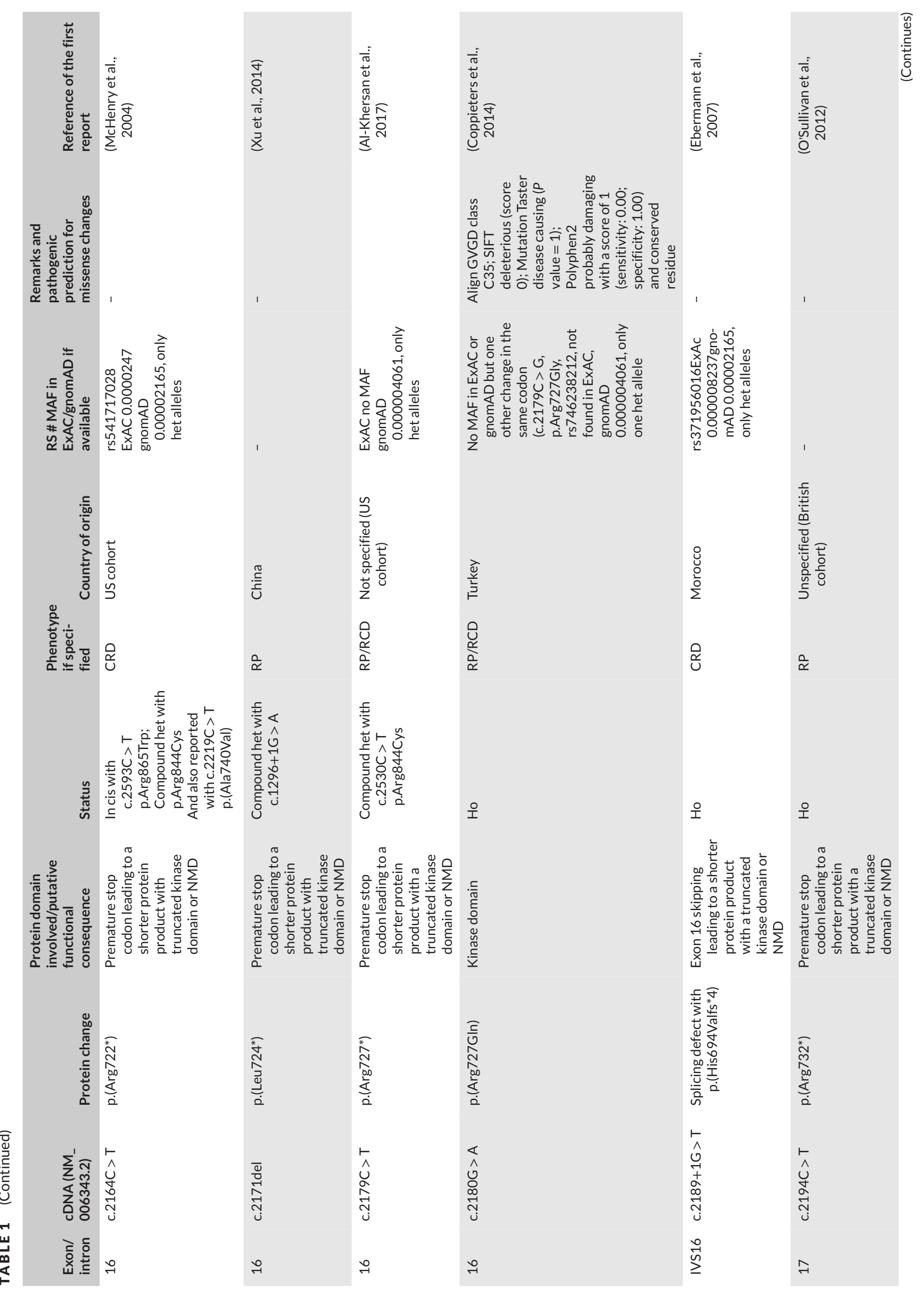




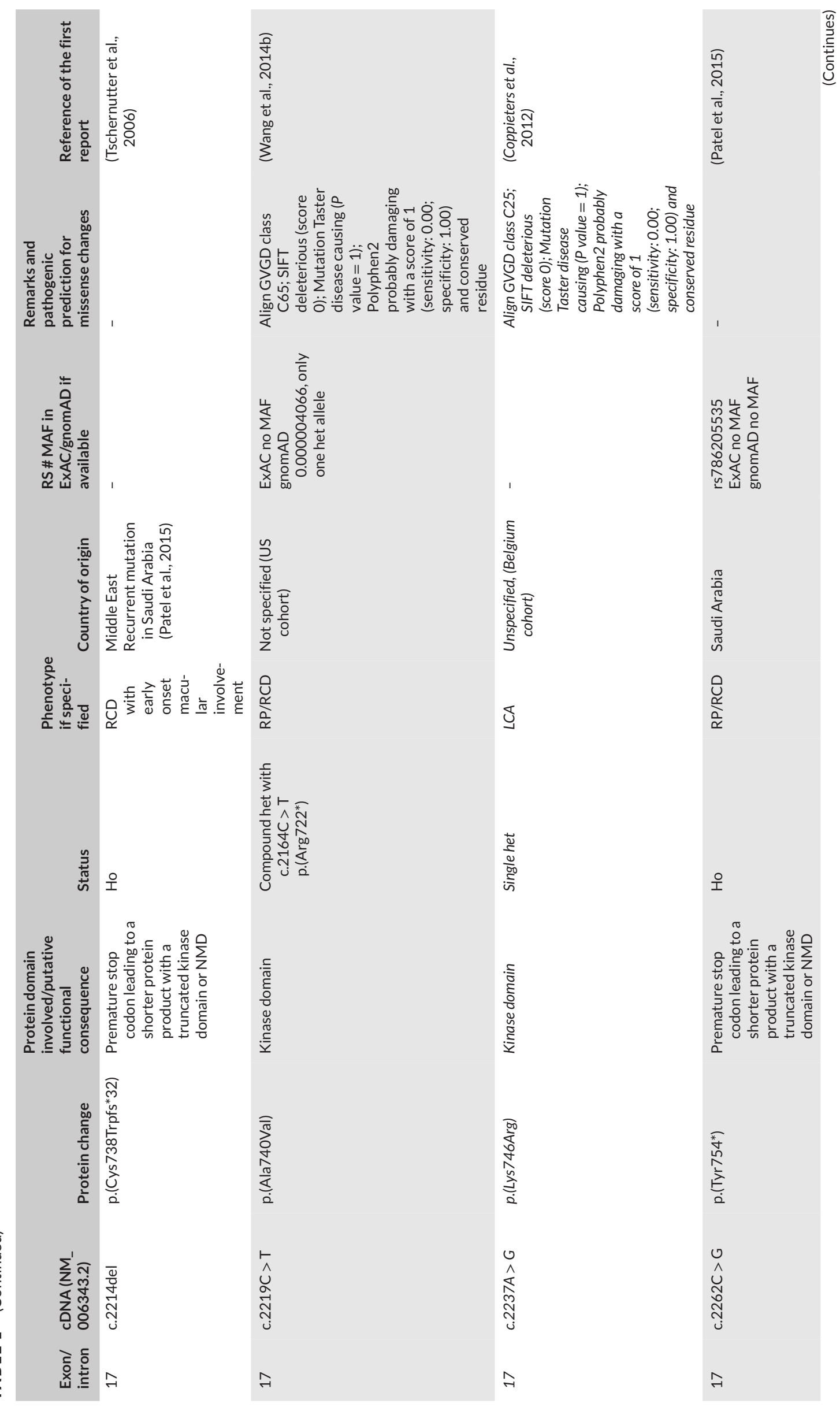




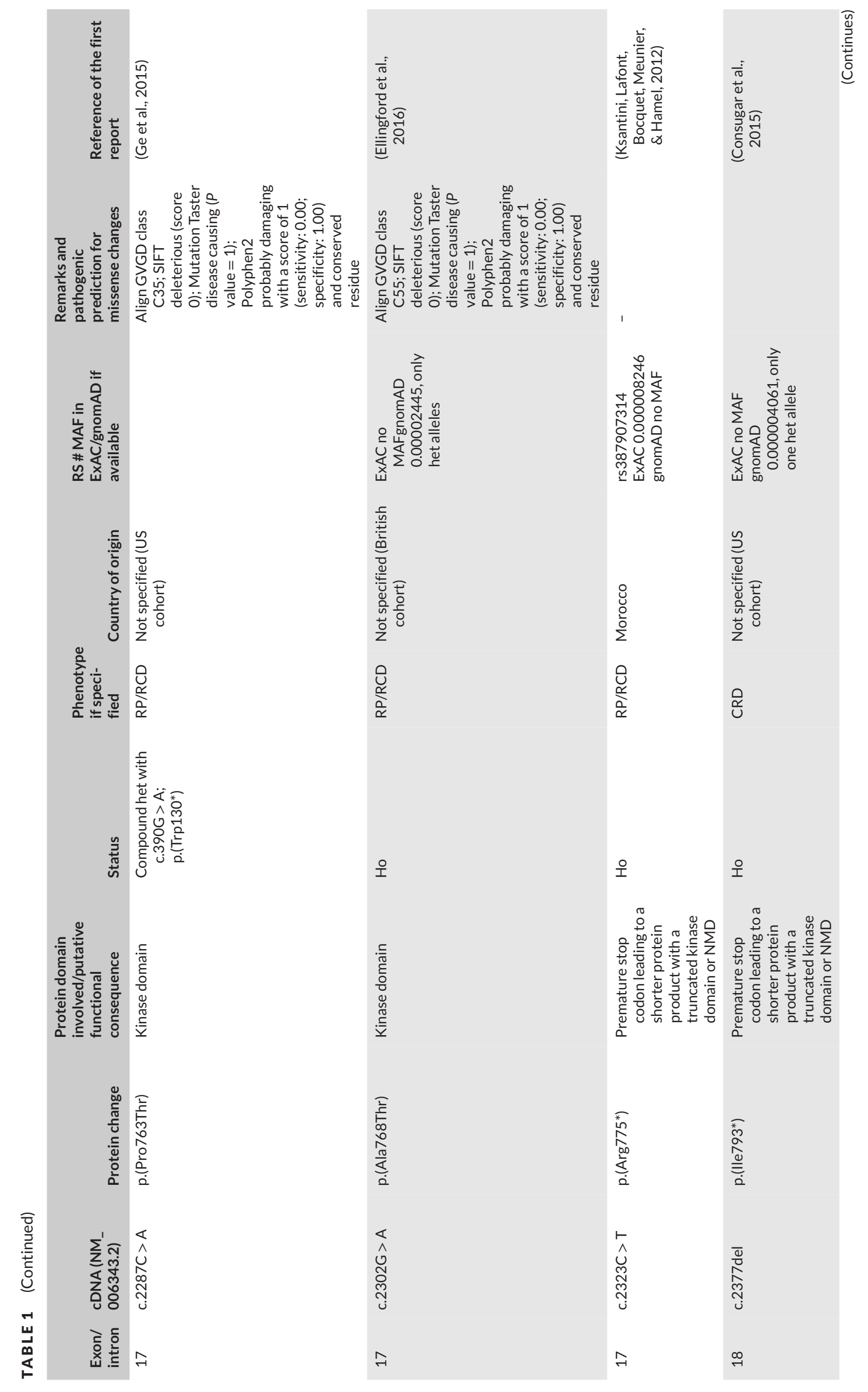




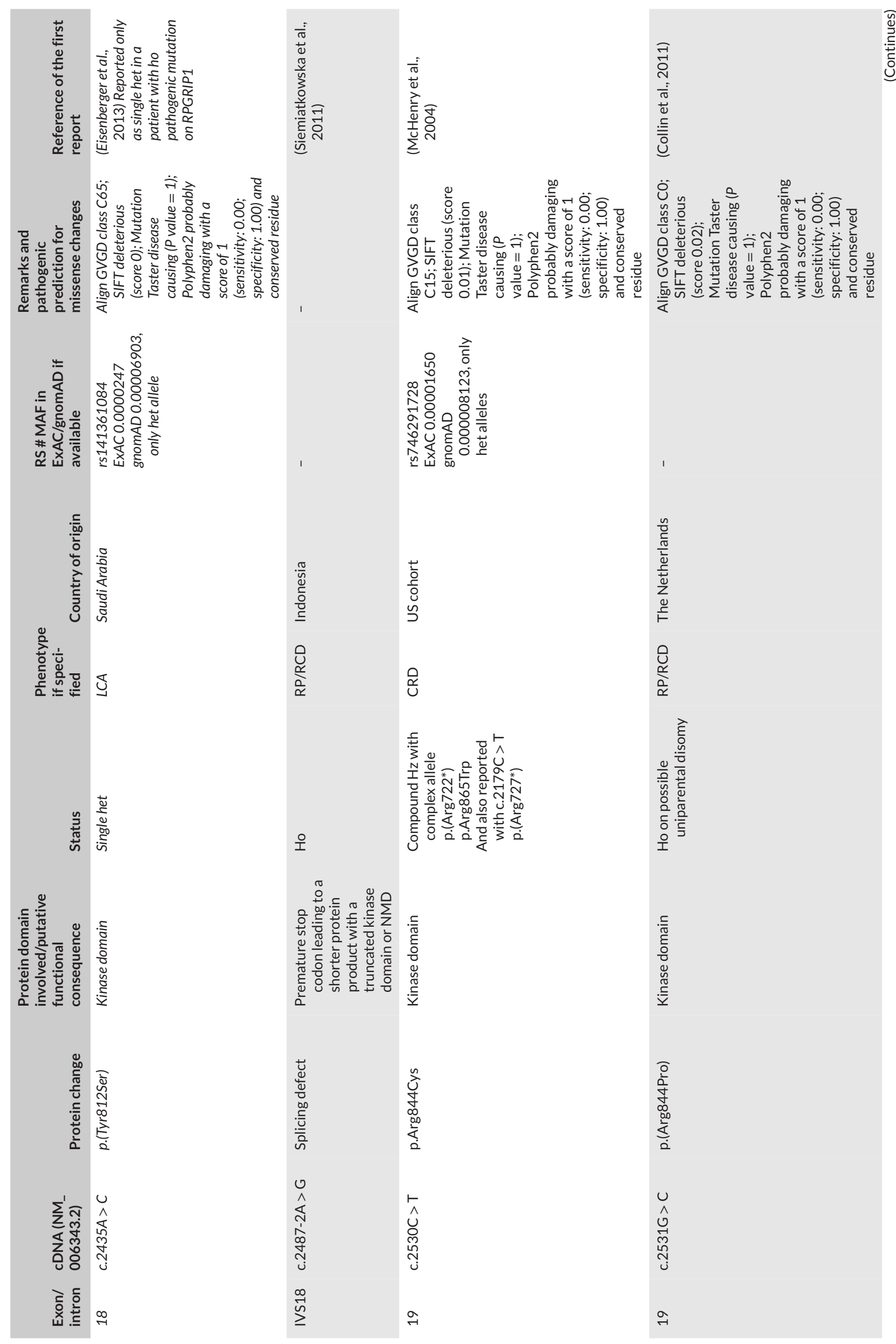




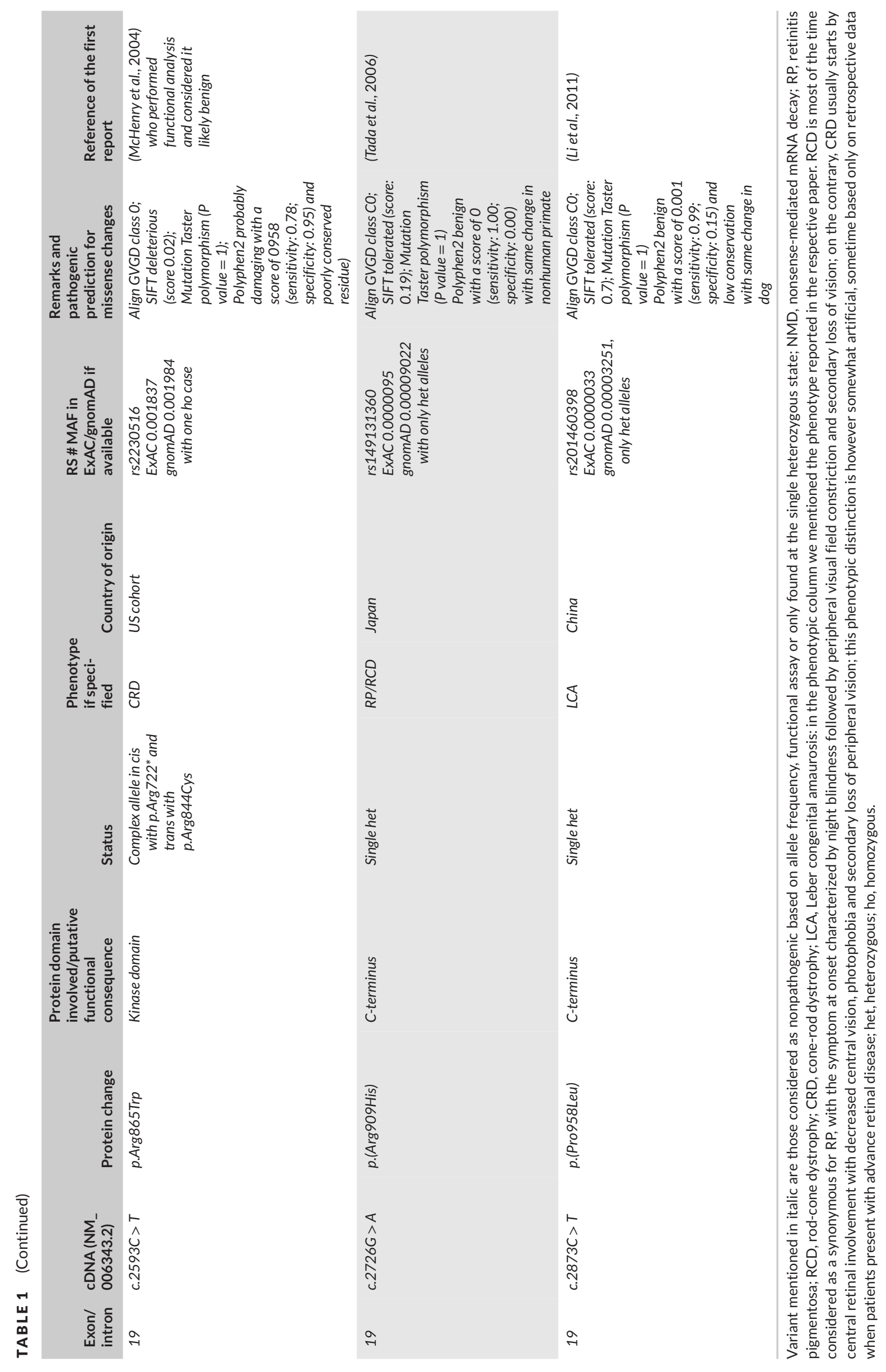


unique except two: the known c.2189+1C>T splice variant (Ebermann et al., 2007) was found in four independent families including three of North African descent and may represent a founder effect in this population and the large exonic deletion encompassing exon 3 to exon 19 that we reported earlier (Boulanger-Scemama et al., 2015), which was found in three unrelated cases including one from African descent (Burkina Faso) and 2 from French descent. Novel mutations include five missense changes, one 2-bp-insertion-deletion also resulting in an amino acid substitution. Three of these amino acid substitutions are located within the Ig-like C2 type 2 domain, one within the first FN-III domain and two within the kinase domain (Figure 1). Amino acid residues involved by these mutations are highly conserved (Figure 2) and the changes induced by the amino acid substitutions are predicted to be pathogenic by prediction programs (Table 1). We found one novel splice site variant (c.2079+2T>G), the sequence being conserved across species (Figure 2). This change is predicted to affect the wild type donor site most probably affecting splicing of intron 15 (Desmet et al., 2009). This may result in the continuation of protein translation after the lysine encoded by the last codon of exon 15 with the addition of 8 amino acid residues before reaching a stop codon. An alternative cryptic site in intron 15 could also be unmasked with also part of intron 15 being translated. In both instances, this would results in a truncation of the protein missing part of the kinase domain or in nonsense-mediated mRNA decay (NMD). Additional novel changes include one 1-bp-deleletion, one 2-bp-deletion, one 1-bp-duplication, and one 4-bp-duplication, all resulting either in a frameshift with premature stop codon and a truncated protein product or NMD. Our findings therefore add 11 novel changes to the 68 variants reported in the literature for a total of 79 reported variants (Table 1) spanning the entire coding and exon-flanking region (Figure 1).

All mutations identified by our comprehensive literature review and described herein, were submitted to the existing Locus Specific Databases (LSDB) on MERTK (https://www.LOVD.nl/ MERTK).

\section{PREVALENCE DATA}

The screening of our cohort including 1,095 RCD and 100 CRD index cases lead to the identification of 25 affected subjects belonging to 20 unrelated families (Supp. Figure S2) who carried likely pathogenic mutations in MERTK including 21 cases of RCD and four cases of CRD. Therefore, mutations in MERTK would account for a prevalence of $\sim 1.7 \%$ IRD families in this large cohort with nearly $4 \%$ in the CRD subgroup. These numbers are comparable with previous reports with prevalence in the literature ranging from 1\% (Huang et al., 2015; Strick \& Vollrath, 2010; Tschernutter et al., 2006), 2\% (Ge et al., 2015), 3\% (Patel et al., 2016) and up to $30 \%$ in the Faroe Islands with a common $91 \mathrm{~kb}$ founder deletion encompassing exons 1 to 7 (Ostergaard, Duno, Batbayli, Vilhelmsen, \& Rosenberg, 2011). Of note, the $4 \%$ prevalence in our CRD should be taken with caution as the distinction between RCD and CRD is often difficult especially in advanced cases and may have been made retrospectively in some cases. This higher prevalence may only reflect the early macular involvement characterizing IRD associated with MERTK mutations.

\section{5 | CLINICAL CHARACTERISTICS OF PATIENTS CARRYING MERTK MUTATIONS}

Mutations in MERTK underlying IRD was first reported by Gal et al. (2000), following the genetic characterization underlying retinal degeneration in the RCS rat (D'Cruz et al., 2000). The associated IRD phenotype is usually severe characterized by an early onset of the disease and rapid macular involvement. The screening of our large IRD cohort (i.e., 1,095 RCD and 100 CRD, with a distinction made retrospectively based on the initial symptoms) identified 25 patients with MERTK mutation whose clinical findings are summarized in Supp. Table S2 with representative retinal images presented in Figure 3. The 25 patients carrying mutations in MERTK were examined including 13 male and 12 female patients, with an age at time of examination ranging from 13 to 60 with an average of 28.76 and a median of 25 . They all experienced onset of symptoms, consisting primarily of night vision disturbances, before 18 with a majority of them during their early teens. Of note, none of the patients had nystagmus, which was only reported once in association with MERTK mutations (McHenry et al., 2004). They all presented with severe retinal abnormalities and early macular involvement consistent with previous reports on IRD associated with MERTK mutations (Charbel Issa et al., 2009; Ebermann et al., 2007; Gal et al., 2000; Jinda et al., 2016; Ksantini, Lafont, Bocquet, Meunier, \& Hamel, 2012; Mackay et al., 2010; McHenry et al., 2004; Thompson et al., 2002; Tschernutter et al., 2006).

Visual acuity ranges from light perception to 20 out of 32 for the youngest patient. Color vision was abnormal in all tested patients (24 out of 25) with 32 eyes showing severe dyschromatopsia, 10 eyes with tritan, two with deutan, and one with protan defects. Visual fields were constricted in all patients with a majority (92\%) reduced to the 20 central degrees or below at the binocular III4e stimulus. All patients had none-detectable full field and multifocal ERG responses in keeping with severe generalized retinal dysfunction for both the rod and cone system with additional severe macular dysfunction. In this respect, the distinction between RCD (21 patients) and CRD (4 patients) could not be made based on functional assessment but mainly on retrospective elements, patients reporting initial decreased central vision, possible photophobia followed by night vision disturbances as inaugural symptoms, and macular atrophy, being classified as CRD. This distinction is however questionable and combined photoreceptor dystrophy could in these cases with severe functional involvement be a better term.

On fundus examination, 20 out of 25 patients had waxy pallor of the optic discs (e.g., Figure $3 \mathrm{~A}$ and $\mathrm{B}$ ), almost all had narrowed retinal vessels (e.g., Figure $3 \mathrm{~A}, \mathrm{~B}$, and $\mathrm{D}$ but not C), 13 out of 25 had a beaten-bronze appearance with very few pigment migrations (e.g., Figure $3 \mathrm{~A}$ and $\mathrm{C}$ ) among which three had subtle white dots in the retinal periphery (e.g., Figure $3 \mathrm{~A}$ and $\mathrm{C}$ ) with one also in the macular area. Along with the early onset macular involvement, the 


\begin{tabular}{|c|c|c|c|c|c|}
\hline & 222 & 262 & 329 & 599 & 721 \\
\hline & $E / D$ & $\mathrm{~F}$ & $\mathrm{~s}$ & $\mathrm{E}$ & $Q$ \\
\hline Human & TCQAVGPPEPV & MAVFSCEAHND & ADPLSNGSVMI & CAGGEFGSVMEG & NRNFLHRDLAA \\
\hline Orangutan & TCQAVGPPEPV & MAVFSCEAHND & ADPLSNGSVMI & CAGGEFGSVMEG & NRNFLHRDLAA \\
\hline Rhesus & TCQAVGPPEPV & MAVFSCEAHND & DPLSNGSVMI & CAGGEFGSVMEG & NRNFLHRDLAA \\
\hline Marmoset & TCQAVGPPEPI & MAVFSCEAHN & DPLSNGSVMI & CAGGEFGSVMEG & NRNFLHRDLAA \\
\hline Dog & TCQAVGPPEPV & AVFSCEAHND & DPLSNGSVM & CAGGEFGSVMEG & NRNFLHRDLAA \\
\hline Cat & TCQAVGPPEPV & MAVFSCEAHND & DPLSNGSVM & CAGGEFGSVMEG & NRNFLHRDLAA \\
\hline Mouse & TCQAVGPPEPV & AVFSCEAHND & AD LSNGSVM & CAGGEFGSVMEG & NRNFLHRDLAA \\
\hline Rat & TCQAVGPPEPV & AVFSCEAHND & AD LSNGSVM & CAGGEFGSVMEG & SRNFLHRDLAA \\
\hline Horse & TCQAVGPPEPV & AVFSCEAHND & DPLSNGSVMI & CAGGEFGSVMEG & NRNFLHRDLAA \\
\hline Opossum & TCQAVGPPEPV & A FSCEAHND & $V S L N S V I$ & AGGEFGSVMEG & NRNFLHRDLAA \\
\hline Platypus & TC AVGPPEPV & SAVFSCEAHND & ADPL N SVM & CAGGEFGSVMEG & SRNFLHRDLAA \\
\hline Chicken & TCQAVGPPEPV & $-\ldots-\ldots$ & A PQSN S SLIL & $--\cdots-1-1$ & $S R \cap F L H R D L A A$ \\
\hline Zebrafish & - - & - & - & - - & SRNFLHRDLAA \\
\hline Lizard & TC AVGPPEPV & A F CEAHN & VVVGDNASVMV & CAGGEFGSVMEG & N KMLHRDLAA \\
\hline $\mathrm{X}$-Tropicalis & TC AVGPPEPV & A FSCEAHN & M-ISSNG VTRY & 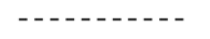 & SRNFLHRLAA \\
\hline \multicolumn{6}{|c|}{$2079+2$} \\
\hline \multicolumn{6}{|c|}{9} \\
\hline Human & \multicolumn{5}{|c|}{ AAAGgtaatga } \\
\hline Rhesus & \multicolumn{5}{|c|}{ AAAGgtaatga } \\
\hline Orangutan & \multicolumn{5}{|c|}{ AAAGgtaatga } \\
\hline Marmoset & \multicolumn{5}{|c|}{ AAAGgtaa--- } \\
\hline Dog & \multicolumn{5}{|c|}{ AAGgtaat a } \\
\hline Cat & \multicolumn{5}{|c|}{ AAGgtaat $a$} \\
\hline Mouse & \multicolumn{5}{|c|}{ AAGgtaacag } \\
\hline Rat & \multicolumn{5}{|c|}{ AAGgtaacag } \\
\hline Horse & \multicolumn{5}{|c|}{ AAAGgtaa ga } \\
\hline Opossum & \multicolumn{5}{|c|}{ AAGgtaat $t a$} \\
\hline Platypus & \multicolumn{5}{|c|}{ CCAGgtaggga } \\
\hline Chicken & \multicolumn{5}{|c|}{ CCAGgtaatga } \\
\hline Zebrafish & \multicolumn{5}{|c|}{ TGTGgtaataa } \\
\hline Lizard & \multicolumn{5}{|c|}{ TCAGgtaat-- } \\
\hline X-Tropicalis & \multicolumn{5}{|c|}{ TCAGgta -a a } \\
\hline
\end{tabular}

FIGURE 2 Evolutionary conservation of likely pathogenic novel missense and splice-site variants identified by our group

beaten-bronze appearance of the fundus and the presence of white dots have been reported before (Charbel Issa et al., 2009; Ebermann et al., 2007; Jinda et al., 2016; Ksantini et al., 2012; Mackay et al., 2010). These white dots are not specific of IRD with MERTK mutations since they have also been reported in association with TULP1, LRAT, RLBP1, RPE65, or RHO mutations among others (Lewis et al., 1999; Littink et al., 2012; Mataftsi et al., 2007; Schatz et al., 2011; Souied et al., 1996). Some of them may by hyperautofluorescent and hyper-reflective on SD-OCT, located at the level of the outer retina (see below).

Short-wave length fundus autofluorescence revealed patchy loss in the periphery for all patients. In addition, none of the patients display the classical ring of increased fundus autofluorescence reported in patients with RCD and preserved macular function (Robson et al., 2003). Instead, all patients had abnormal autofluorescence at the macula with two distinct patterns (Figure 3): 14 out of 25 patients had foveal increase of autofluorescence (e.g., Figure 3A), whereas the rest had loss of autofluorescence in the macula (e.g., Figure $3 C$ and D). In addition, 12 out of 25 patients had fine hyperautofluorescent dots including eight with increased autofluorescence of the fovea (e.g., Figure 3B). Consistently, patients with loss of macular autofluorescence had severe outer central retinal thinning on SD-OCT unlike those with increased foveal autofluorescence. Of note, four out of 25 patients presented with mild epiretinal membranes but no obvious vitreomacu- lar tractions on SD-OCT requiring surgery. Besides these four patients, we did not notice the wrinkled appearance of the inner retina on fundus examination reported by Charbel Issa et al. (2009) associated to a peculiar wave-like appearance of the innermost neurosensory retina on SD-OCT. None of the patients with MERTK mutations had preservation of the outer retinal hyper-reflective bands (i.e., external limiting membrane, ellipsoid, and interdigitation zones). They all display hyperreflective dots above the RPE/Bruch's membrane complex (e.g., zoom in Figure $3 \mathrm{~A}$ and $\mathrm{C}$ ). In addition, 24 out of 25 patients had evidence of hyper-reflective dots (e.g., zoom in Figure $3 \mathrm{~A}$ and $\mathrm{C}$ ) in the choroid which has, to our knowledge, never been noticed before although they are visible on SD-OCT figures from recent papers (Charbel Issa et al., 2009; Jinda et al., 2016). Some of the dots located in the outer retina may correspond to the hyperautofluorescent dots on FAF seen on some of the patients and maybe to the occasional white dots seen on fundus examination. These dots may represent outer segment debris, RPE cell migration or/and phagocytes (i.e., macrophages and activated microglia) also seen in RCS rats (Dowling \& Sidman, 1962; LaVail, Pinto, \& Yasumura, 1981) and Mertk knockout mice (Duncan et al., 2003). In keeping with this, a recent study applying two photon microscopy to various Mertk-/- mutant models suggested that microglial cells could be recruited to transport byproducts of the phototransduction cascade to the RPE and be involved in the elimination of dying photoreceptor cells (Palczewska et al., 2016). Macrophages may also account for the 

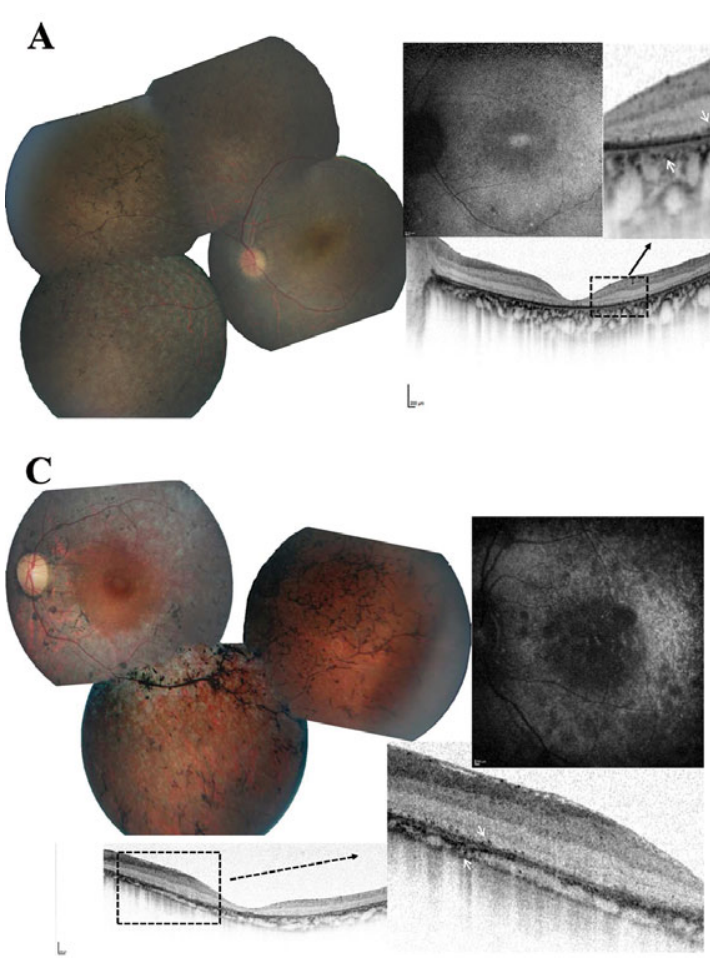

B
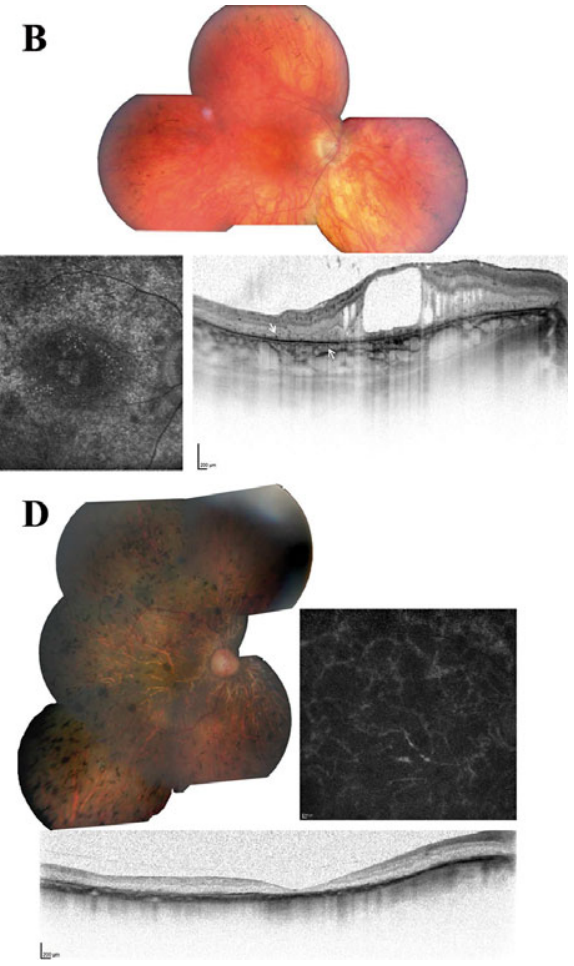

FIGURE 3 Retinal images illustrating the phenotypic variability of inherited retinal diseases associated with MERTK mutations. A: Left eye of CIC00568: color fundus photograph (left) reveals a moderately pale optic disc; narrowed retinal vessels, a beaten-bronze appearance of the retinal periphery with only very few bone spicules; fundus autofluorescence (FAF) imaging (middle) shows a foveal increase of autofluorescence surrounded by a patchy loss of autofluorescence and some hyperautofluorescent dots; Spectral domain-optical coherence tomography (SD-OCT) (right with close-up) reveals a thinning of the outer nuclear layer, hyper-reflective dots above the RPE/Bruch complex and within the choroid (white arrows) with no visible external limiting membrane (ELM), ellipsoid zone (EZ), and interdigitation zone (IDZ). B: Right eye of CIC04456: color fundus photograph (top) reveals a pale optic disc, narrowed retinal vessels, an albinoid fundus with very few bone spicules and cystoid macular changes; FAF imaging (bottom left) shows severe diffused patchy loss of FAF including the macula with fine hyperAF dots; SD-OCT (bottom right) reveals intraretinal cysts with no visible ELM, EZ, or IDZ associated with hyper-reflective dots above the RPE/Bruch complex and in choroid (white arrows). C: Left eye of CIC03112: color fundus photograph (top left) reveals a well colored optic nerve, no narrowed retinal vessels, beaten-bronze appearance in the periphery with only few bone spicules, pigment clumping in the macula; FAF imaging (top right) shows severe diffused patchy loss of FAF including the macula with fine hyperautofluorescent dots; SD-OCT (bottom with close-up) reveals a severe outer retinal thinning with hyperreflective dots above a thinned RPE/Bruch complex and in choroid (white arrows). D: Right eye of CIC04949: color fundus photograph (top left) reveals a well colored optic disc, narrowed retinal vessels and diffuse pigment clumping; FAF imaging (top right) shows a diffuse patchy loss of FAF including the fovea; SD-OCT (bottom) reveals severe thinning of the outer retina with some hyper-reflective dots above the thinned RPE/Bruch complex but a thinned choroid with no obvious dots

hyperflective dots seen in the choroid. These hyper-reflective dots are not specific of IRD linked to MERTK mutations. They have also been reported in association with Stargardt disease (Ge et al., 2015), Bietti crystalline dystrophy, independently of crystal location (Saatci, Doruk, Yaman, \& Oner, 2014), and RCD (Kuroda et al., 2014). In the latter, Kuroda et al. (2014) suggested that these hyper-reflective dots were associated with disease progression. However, no genotype was available in this publication therefore the occurrence of outer retinal hyperreflective dots in correlation with specific gene defects in IRD remains to be established. If they indeed represent phagocytic cells, these dots may have some incidence in a putative inflammatory response to treatment such as cell therapy.

Altogether, the association with early onset IRD with macular involvement associated with a bronze-beaten appearance, several white spots on fundoscopy, abnormal macular FAF, lack of preservation of outer retinal hyper-reflective bands with hyper-reflective dots in the outer retina and the choriocapilaris may be suggestive but not specific of a MERTK-related IRD in a sporadic or autosomal recessive case.

Although the present cohort is one of the largest reported in the literature on patients with retinal dystrophy related with MERTK mutations, we were not able to draw any specific conclusion on phenotype/genotype correlations, most likely due to the diversity of the mutation spectrum in a yet limited number of patients. Intriguingly, patients from two distinct families (F751 and F3928) were carrying the same large deletion. Individuals for F751 had a CRD phenotype with early onset decreased vision and photophobia whereas the individual from F3928 had more a RCD phenotype. In addition, one of the patients with the most severe phenotype (CIC00239) was carrying two missense mutations. There may be additional factors, genetic or environmental that may also impact on the phenotype as suggested by Vollrath et al. (2015). Larger cohort studies and natural history of the disease may help better define such correlations. 


\section{6 | FUTURE DIRECTIONS}

Our work expands the mutation spectrum of MERTK in IRD which spans the entire coding and splice regions of the gene. It sets basis for therapeutic intervention aiming at gene augmentation (Ghazi et al., 2016; LaVail, et al., 2016) or cell therapy (Jones, Lu, Girman, \& Wang, 2017) for this genetic group linked to mutations in a selectively RPEexpressed gene. Mutations in MERTK are however associated with early onset retinal degeneration with rapid macular involvement urging for early diagnosis and intervention in strategies aiming at rescuing photoreceptors. Natural history studies with longitudinal followup may help better define therapeutic strategies and window of intervention.

\section{ACKNOWLEDGMENTS}

The authors thank the patients and their family participating in the study and the clinical staff from the CIC1423. DNA samples incorporated in this study were obtained from the NeuroSensCol DNA bank, for research in neuroscience (PI: JA Sahel, co-PI I Audo, partner with CHNO des Quinze-Vingts, Inserm and CNRS).

\section{DISCLOSURE STATEMENT}

The authors declare no conflict of interest.

\section{ORCID}

Isabelle Audo (iD http://orcid.org/0000-0003-0698-5309

Cécile Méjécase iD http://orcid.org/0000-0003-2532-4004

Said El Shamieh (D) http://orcid.org/0000-0002-8522-0445

José-Alain Sahel (D) http://orcid.org/0000-0002-4831-1153

Christina Zeitz (D) http://orcid.org/0000-0002-3510-1712

\section{REFERENCES}

Adzhubei, I. A., Schmidt, S., Peshkin, L., Ramensky, V. E., Gerasimova, A., Bork, P., ... Sunyaev, S. R. (2010). A method and server for predicting damaging missense mutations. Nature Methods, 7(4), 248-249.

Ahonen, S. J., Arumilli, M., Seppala, E., Hakosalo, O., Kaukonen, M. K., Komaromy, A. M., \& Lohi, H. (2014). Increased expression of MERTK is associated with a unique form of canine retinopathy. Plos One, 9(12), e114552.

Aldahmesh, M. A., Safieh, L. A., Alkuraya, H., Al-Rajhi, A., Shamseldin, H., Hashem, M., ... Alkuraya, F. S. (2009). Molecular characterization of retinitis pigmentosa in Saudi Arabia. Molecular Vision, 15, 2464-2469.

Al-Khersan, H., Shah, K. P., Jung, S. C., Rodriguez, A., Madduri, R. K., \& Grassi, M. A. (2017). A novel MERTK mutation causing retinitis pigmentosa. Graefes Archive for Clinical and Experimental Ophthalmology,

Audo, I., Bujakowska, K. M., Leveillard, T., Mohand-Said, S., Lancelot, M. E., Germain, A., ... Zeitz, C. (2012). Development and application of a nextgeneration-sequencing (NGS) approach to detect known and novel gene defects underlying retinal diseases. Orphanet Journal of Rare Diseases, 7 , 8.

Audo, I., Sahel, J. A., Mohand-Said, S., Lancelot, M. E., Antonio, A., MoskovaDoumanova, V., ... Zeitz, C. (2010). EYS is a major gene for rod-cone dystrophies in France. Human Mutation, 31(5), E1406-35.
Bok, D., \& Hall, M. O. (1971). The role of the pigment epithelium in the etiology of inherited retinal dystrophy in the rat. Journal of Cell Biology, 49(3), 664-682.

Boulanger-Scemama, E., El Shamieh, S., Demontant, V., Condroyer, C., Antonio, A., Michiels, C., ... Audo, I. (2015). Next-generation sequencing applied to a large French cone and cone-rod dystrophy cohort: Mutation spectrum and new genotype-phenotype correlation. Orphanet Journal of Rare Diseases, 10, 85.

Charbel Issa, P., Bolz, H. J., Ebermann, I., Domeier, E., Holz, F. G., \& Scholl, H. P. (2009). Characterisation of severe rod-cone dystrophy in a consanguineous family with a splice site mutation in the MERTK gene. British Journal of Ophthalmology, 93(7), 920-925.

Collin, R. W., van den Born, L. I., Klevering, B. J., de Castro-Miro, M., Littink, K. W., Arimadyo, K., ... Cremers, F. P. (2011). High-resolution homozygosity mapping is a powerful tool to detect novel mutations causative of autosomal recessive RP in the Dutch population. Investigative Ophthalmology \& Visual Science, 52(5), 2227-2239.

Consugar, M. B., Navarro-Gomez, D., Place, E. M., Bujakowska, K. M., Sousa, M. E., Fonseca-Kelly, Z. D., ... Pierce, E. A. (2015). Panel-based genetic diagnostic testing for inherited eye diseases is highly accurate and reproducible, and more sensitive for variant detection, than exome sequencing. Genetics in Medicine, 17(4), 253-261.

Coppieters, F., De Wilde, B., Lefever, S., De Meester, E., De Rocker, N., Van Cauwenbergh, C., ... De Baere, E. (2012). Massively parallel sequencing for early molecular diagnosis in Leber congenital amaurosis. Genetics in Medicine, 14(6), 576-585.

Coppieters, F., Van Schil, K., Bauwens, M., Verdin, H., De Jaegher A, Syx D., Sante, T., ... De Baere, E. (2014). Identity-by-descent-guided mutation analysis and exome sequencing in consanguineous families reveals unusual clinical and molecular findings in retinal dystrophy. Genetics in Medicine, 16(9), 671-680.

D'Cruz, P. M., Yasumura, D., Weir, J., Matthes, M. T., Abderrahim, H., LaVail, M. M., \& Vollrath, D. (2000). Mutation of the receptor tyrosine kinase gene Mertk in the retinal dystrophic RCS rat. Human Molecular Genetics, 9(4), 645-651.

Desmet, F. O., Hamroun, D., Lalande, M., Collod-Beroud, G., Claustres, M., \& Beroud, C. (2009). Human Splicing Finder: An online bioinformatics tool to predict splicing signals. Nucleic Acids Research, 37(9), e67.

Dowling, J. E., \& Sidman, R. L. (1962). Inherited retinal dystrophy in the rat. Journal of Cell Biology, 14, 73-109.

Duncan, J. L., LaVail, M. M., Yasumura, D., Matthes, M. T., Yang, H., Trautmann, N., ... Vollrath, D. (2003). An RCS-like retinal dystrophy phenotype in mer knockout mice. Investigative Ophthalmology \& Visual Science, 44(2), 826-838.

Ebermann, I., Walger, M., Scholl, H. P., Charbel Issa, P., Luke, C., Nurnberg, G., ... Bolz, H. J. (2007). Truncating mutation of the DFNB59 gene causes cochlear hearing impairment and central vestibular dysfunction. Human Mutation, 28(6), 571-577.

Edwards, R. B., \& Szamier, R. B. (1977). Defective phagocytosis of isolated rod outer segments by RCS rat retinal pigment epithelium in culture. Science, 197(4307), 1001-1003.

Eisenberger, T., Neuhaus, C., Khan, A. O., Decker, C., Preising, M. N., Friedburg, C., ... Bolz, H. J. (2013). Increasing the yield in targeted nextgeneration sequencing by implicating CNV analysis, non-coding exons and the overall variant load: The example of retinal dystrophies. Plos One, 8(11), e78496.

Ellingford, J. M., Barton, S., Bhaskar, S., O'Sullivan, J., Williams, S. G., Lamb, J. A., ... Black, Graeme C. M. (2016). Molecular findings from 537 individuals with inherited retinal disease. Journal of Medical Genetics, 53(11), 761-767.

Evans, D. R., Green, J. S., Johnson, G. J., Schwartzentruber, J., Majewski, J., Beaulieu, C. L., ... Woods, M. O., FORGE Canada Consortium. (2017). 
Novel $25 \mathrm{~kb}$ deletion of MERTK causes retinitis pigmentosa with severe progression. Investigative Ophthalmology \& Visual Science, 58(3), 17361742.

Feng, W., Yasumura, D., Matthes, M. T., LaVail, M. M., \& Vollrath, D. (2002). Mertk triggers uptake of photoreceptor outer segments during phagocytosis by cultured retinal pigment epithelial cells. Journal of Biological Chemistry, 277(19), 17016-17022.

Gal, A., Li, Y., Thompson, D. A., Weir, J., Orth, U., Jacobson, S. G., ... Vollrath, D. (2000). Mutations in MERTK, the human orthologue of the RCS rat retinal dystrophy gene, cause retinitis pigmentosa. Nature Genetics, 26(3), 270-271.

Ge, Z., Bowles, K., Goetz, K., Scholl, H. P., Wang, F., Wang, X., ... Chen, R. (2015). NGS-based molecular diagnosis of 105 eyeGENE((R)) probands with retinitis pigmentosa. Scientific Reports, 5, 18287.

Ghazi, N. G., Abboud, E. B., Nowilaty, S. R., Alkuraya, H., Alhommadi, A., Cai, H., ... Alkuraya, F. S. (2016). Treatment of retinitis pigmentosa due to MERTK mutations by ocular subretinal injection of adeno-associated virus gene vector: Results of a phase I trial. Human Genetics, 135(3), 327-343.

Hartong, D. T., Berson, E. L., \& Dryja, T. P. (2006). Retinitis pigmentosa. Lancet, 368(9549), 1795-1809.

Herron, W. L., Riegel, B. W., Myers, O. E., \& Rubin, M. L. (1969). Retinal dystrophy in the rat-a pigment epithelial disease. Investigative Ophthalmology, 8(6), 595-604.

Huang, X. F., Huang, F., Wu, K. C., Wu, J., Chen, J., Pang, C. P., ... Jin, Z. B. (2015). Genotype-phenotype correlation and mutation spectrum in a large cohort of patients with inherited retinal dystrophy revealed by next-generation sequencing. Genetics in Medicine, 17(4), 271278.

Jinda, W., Poungvarin, N., Taylor, T. D., Suzuki, Y., Thongnoppakhun, W., Limwongse, C., ... Atchaneeyasakul, L. O. (2016). A novel start codon mutation of the MERTK gene in a patient with retinitis pigmentosa. Molecular Vision, 22, 342-351.

Jones, M. K., Lu, B., Girman, S., \& Wang, S. (2017). Cell-based therapeutic strategies for replacement and preservation in retinal degenerative diseases. Progress in Retinal and Eye Research, 58, 1-27.

Kevany, B. M., \& Palczewski, K. (2010). Phagocytosis of retinal rod and cone photoreceptors. Physiology (Bethesda), 25(1), 8-15.

Khan, K. N., Chana, R., Ali, N., Wright, G., Webster, A. R., Moore, A. T., \& Michaelides, M. (2017). Advanced diagnostic genetic testing in inherited retinal disease: Experience from a single tertiary referral centre in the UK National Health Service. Clinical Genetics, 91(1), 38-45.

Koenekoop, R. K., Lopez, I., den Hollander, A. I., Allikmets, R., \& Cremers, F. P. (2007). Genetic testing for retinal dystrophies and dysfunctions: Benefits, dilemmas and solutions. Clinical \& Experimental Ophthalmology, 35(5), 473-485.

Ksantini, M., Lafont, E., Bocquet, B., Meunier, I., \& Hamel, C. P. (2012). Homozygous mutation in MERTK causes severe autosomal recessive retinitis pigmentosa. European Journal of Ophthalmology, 22(4), 647653.

Kumar, P., Henikoff, S., \& Ng, P. C. (2009). Predicting the effects of coding non-synonymous variants on protein function using the SIFT algorithm. Nature Protocols, 4(7), 1073-1081.

Kuroda, M., Hirami, Y., Hata, M., Mandai, M., Takahashi, M., \& Kurimoto, Y. (2014). Intraretinal hyperreflective foci on spectral-domain optical coherence tomographic images of patients with retinitis pigmentosa. Clinical Ophthalmology, 8, 435-440.

LaVail, M. M., \& Battelle, B. A. (1975). Influence of eye pigmentation and light deprivation on inherited retinal dystrophy in the rat. Experimental Eye Research, 21(2), 167-192.
LaVail, M. M., Pinto, L. H., \& Yasumura, D. (1981). The interphotoreceptor matrix in rats with inherited retinal dystrophy. Investigative Ophthalmology \& Visual Science, 21(5), 658-668.

LaVail, M. M., Yasumura, D., Matthes, M. T., Yang, H., Hauswirth, W. W., Deng, W. T., \& Vollrath, D. (2016). Gene Therapy for MERTK-Associated Retinal Degenerations. Advances in Experimental Medicine and Biology, 854, 487-493.

Law, A. L., Parinot, C., Chatagnon, J., Gravez, B., Sahel, J. A., Bhattacharya, S. S., \& Nandrot, E. F. (2015). Cleavage of Mer tyrosine kinase (MerTK) from the cell surface contributes to the regulation of retinal phagocytosis. Journal of Biological Chemistry, 290(8), 4941-4952.

Lemke, G. (2013). Biology of the TAM receptors. Cold Spring Harbor Perspectives in Biology, 5(11), a009076.

Lewis, C. A., Batlle, I. R., Batlle, K. G., Banerjee, P., Cideciyan, A. V., Huang, J., ... Jacobson, S. G. (1999). Tubby-like protein 1 homozygous splice-site mutation causes early-onset severe retinal degeneration. Investigative Ophthalmology \& Visual Science, 40(9), 2106-2114.

Li, L. X., \& Turner, J. E. (1988). Inherited retinal dystrophy in the RCS rat: Prevention of photoreceptor degeneration by pigment epithelial cell transplantation. Experimental Eye Research, 47(6), 911-917.

Li, L., Xiao, X., Li, S., Jia, X., Wang, P., Guo, X., ... Hejtmancik, J. F. (2011). Detection of variants in 15 genes in 87 unrelated Chinese patients with Leber congenital amaurosis. Plos One, 6(5), e19458.

Ling, L., Templeton, D., \& Kung, H. J. (1996). Identification of the major autophosphorylation sites of Nyk/Mer, an NCAM-related receptor tyrosine kinase. Journal of Biological Chemistry, 271(31), 1835518362.

Littink, K. W., van Genderen, M. M., van Schooneveld, M. J., Visser, L., Riemslag, F. C., Keunen, J. E., ... van den Born, L. I. (2012). A homozygous frameshift mutation in LRAT causes retinitis punctata albescens. Ophthalmology, 119(9), 1899-1906.

Lukovic, D., Artero Castro, A., Delgado, A. B., Bernal Mde, L., Luna Pelaez, N., Diez Lloret, A., ... Bhattacharya, Shomi S. (2015). Human iPSC derived disease model of MERTK-associated retinitis pigmentosa. Scientific Reports, 5, 12910.

Mackay, D. S., Henderson, R. H., Sergouniotis, P. I., Li, Z., Moradi, P., Holder, G. E., ... Moore, A. T. (2010). Novel mutations in MERTK associated with childhood onset rod-cone dystrophy. Molecular Vision, 16, 369377.

Mackay, D. S., Henderson, R. H., Sergouniotis, P. I., Li, Z., Moradi, P., Holder, G. E., ... Moore, Anthony T. (2010). Novel mutations in MERTK associated with childhood onset rod-cone dystrophy. Molecular Vision, 16, 369-377.

Mandal, M. N., Heckenlively, J. R., Burch, T., Chen, L., Vasireddy, V., Koenekoop, R. K., ... Ayyagari, R. (2005). Sequencing arrays for screening multiple genes associated with early-onset human retinal degenerations on a high-throughput platform. Investigative Ophthalmology \& Visual Science, 46(9), 3355-3362.

Mataftsi, A., Schorderet, D. F., Chachoua, L., Boussalah, M., Nouri, M. T., Barthelmes, D., ... Munier, F. L. (2007). Novel TULP1 mutation causing leber congenital amaurosis or early onset retinal degeneration. Investigative Ophthalmology \& Visual Science, 48(11), 5160-5167.

Mazzoni, F., Safa, H., \& Finnemann, S. C. (2014). Understanding photoreceptor outer segment phagocytosis: Use and utility of RPE cells in culture. Experimental Eye Research, 126, 51-60.

McHenry, C. L., Liu, Y., Feng, W., Nair, A. R., Feathers, K. L., Ding, X., ... Thompson, D. A. (2004). MERTK arginine-844-cysteine in a patient with severe rod-cone dystrophy: Loss of mutant protein function in transfected cells. Investigative Ophthalmology \& Visual Science, 45(5), 14561463. 
Mendez-Vidal, C., Bravo-Gil, N., Gonzalez-Del Pozo, M., Vela-Boza, A. Dopazo, J., Borrego, S., \& Antinolo, G. (2014). Novel RP1 mutations and a recurrent BBS1 variant explain the co-existence of two distinct retinal phenotypes in the same pedigree. BMC Genetics [Electronic Resource], 15, 143.

Nandrot, E., Dufour, E. M., Provost, A. C., Péquignot, M. O., Bonnel, S., Gogat, K., ... Abitbol, M. M. (2000). Homozygous deletion in the coding sequence of the c-mer gene in RCS rats unravels general mechanisms of physiological cell adhesion and apoptosis. Neurobiology of Disease 7(6 Pt B):586-599.

Nandrot, E. F., Kim, Y., Brodie, S. E., Huang, X., Sheppard, D., Finnemann, S. C. (2004). Loss of synchronized retinal phagocytosis and age-related blindness in mice lacking alphavbeta5 integrin. Journal of Experimental Medicine. 200(12):1539-1545.

Nandrot, E. F., Silva, K. E., Scelfo, C., Finnemann, S. C. (2012) Retinal pigment epithelial cells use a MerTK-dependent mechanism to limit the phagocytic particle binding activity of $\alpha \mathrm{v} \beta 5$ integrin. Biology of the Cell. 104(6):326-341.

Oishi, M., Oishi, A., Gotoh, N., Ogino, K., Higasa, K., lida, K., ... Yoshimura, N. (2014). Comprehensive molecular diagnosis of a large cohort of Japanese retinitis pigmentosa and Usher syndrome patients by nextgeneration sequencing. Investigative Ophthalmology \& Visual Science, 55(11), 7369-7375.

Ostergaard, E., Duno, M., Batbayli, M., Vilhelmsen, K., \& Rosenberg, T. (2011). A novel MERTK deletion is a common founder mutation in the Faroe Islands and is responsible for a high proportion of retinitis pigmentosa cases. Molecular Vision, 17, 1485-1492.

O'Sullivan, J., Mullaney, B. G., Bhaskar, S. S., Dickerson, J. E., Hall, G., O'Grady, A., ... Black, G. C. (2012). A paradigm shift in the delivery of services for diagnosis of inherited retinal disease. Journal of Medical Genetics, 49(5), 322-326.

Palczewska, G., Maeda, A., Golczak, M., Arai, E., Dong, Z., Perusek, L., ... Palczewski, K. (2016). Receptor MER tyrosine kinase proto-oncogene (MERTK) is not required for transfer of bis-retinoids to the retinal pigmented epithelium. Journal of Biological Chemistry, 291(52), 2693726949

Patel, N., Aldahmesh, M. A., Alkuraya, H., Anazi, S., Alsharif, H., Khan, A. O., ... Alkuraya, F. S. (2015). Expanding the clinical, allelic, and locus heterogeneity of retinal dystrophies. Genetics in Medicine, 18(6), 554-562.

Patel, N., Aldahmesh, M. A., Alkuraya, H., Anazi, S., Alsharif, H., Khan, A. O., ... Alkuraya, F. S. (2016). Expanding the clinical, allelic, and locus heterogeneity of retinal dystrophies. Genetics in Medicine, 18(6), 554-562.

Piri, N., Nesmith, B. L., \& Schaal, S. (2015). Choroidal hyperreflective foci in Stargardt disease shown by spectral-domain optical coherence tomography imaging: Correlation with disease severity. JAMA Ophthalmology, 133(4), 398-405.

Reese, M. G., Eeckman, F. H., Kulp, D., \& Haussler, D. (1997). Improved splice site detection in Genie. Journal of Computational Biology, 4(3), 311323.

Richards, S., Aziz, N., Bale, S., Bick, D., Das, S., Gastier-Foster, J., ... Rehm, H. L. ACMG Laboratory Quality Assurance Committee. (2015). Standards and guidelines for the interpretation of sequence variants: A joint consensus recommendation of the American College of Medical Genetics and Genomics and the Association for Molecular Pathology. Genetics in Medicine, 17(5), 405-424.

Riera, M., Navarro, R., Ruiz-Nogales, S., Mendez, P., Bures-Jelstrup, A., Corcostegui, B., \& Pomares, E. (2017). Whole exome sequencing using Ion Proton system enables reliable genetic diagnosis of inherited retinal dystrophies. Scientific Reports, 7, 42078.

Robson, A. G., El-Amir, A., Bailey, C., Egan, C. A., Fitzke, F. W., Webster, A. R., ... Holder, G. E. (2003). Pattern ERG correlates of abnormal fundus aut- ofluorescence in patients with retinitis pigmentosa and normal visual acuity. Investigative Ophthalmology \& Visual Science, 44(8), 3544-3550.

Saatci, A. O., Doruk, H. C., Yaman, A., \& Oner, F. H. (2014). Spectral domain optical coherence tomographic findings of bietti crystalline dystrophy. Journal of Ophthalmology, 2014, 739271.

Sather, S., Kenyon, K. D., Lefkowitz, J. B., Liang, X., Varnum, B. C., Henson, P. M., \& Graham, D. K. (2007). A soluble form of the Mer receptor tyrosine kinase inhibits macrophage clearance of apoptotic cells and platelet aggregation. Blood, 109(3), 1026-1033.

Schatz, P., Preising, M., Lorenz, B., Sander, B., Larsen, M., \& Rosenberg, T. (2011). Fundus albipunctatus associated with compound heterozygous mutations in RPE65. Ophthalmology, 118(5), 888-894.

Schwarz, J. M., Cooper, D. N., Schuelke, M., \& Seelow, D. (2014). MutationTaster2: Mutation prediction for the deep-sequencing age. Nature Methods, 11(4), 361-362.

Shahzadi, A., Riazuddin, S. A., Ali, S., Li, D., Khan, S. N., Husnain, T., ... Riazuddin, S. (2010). Nonsense mutation in MERTK causes autosomal recessive retinitis pigmentosa in a consanguineous Pakistani family. British Journal of Ophthalmology, 94(8), 1094-1099.

Siemiatkowska, A. M., Arimadyo, K., Moruz, L. M., Astuti, G. D., de CastroMiro, M., Zonneveld, M. N., ... Collin, Rob W. J. (2011). Molecular genetic analysis of retinitis pigmentosa in Indonesia using genome-wide homozygosity mapping. Molecular Vision, 17, 3013-3024.

Souied, E., Soubrane, G., Benlian, P., Coscas, G. J., Gerber, S., Munnich, A., \& Kaplan, J. (1996). Retinitis punctata albescens associated with the Arg135Trp mutation in the rhodopsin gene. American Journal of Ophthalmology, 121(1), 19-25.

Srilekha, S., Arokiasamy, T., Srikrupa, N. N., Umashankar, V., Meenakshi, S., Sen, P., ... Soumittra, N. (2015). Homozygosity mapping in Leber congenital amaurosis and autosomal recessive retinitis pigmentosa in South Indian families. Plos One, 10(7), e0131679.

Strick, D. J., \& Vollrath, D. (2010). Focus on molecules: MERTK. Experimental Eye Research, 91(6), 786-787.

Tada, A., Wada, Y., Sato, H., Itabashi, T., Kawamura, M., Tamai, M., \& Nishida, K. (2006). Screening of the MERTK gene for mutations in Japanese patients with autosomal recessive retinitis pigmentosa. Molecular Vision, 12, 441-444.

Tavtigian, S. V., Deffenbaugh, A. M., Yin, L., Judkins, T., Scholl, T., Samollow, P. B., ... Thomas, A. (2006). Comprehensive statistical study of 452 BRCA1 missense substitutions with classification of eight recurrent substitutions as neutral. Journal of Medical Genetics, 43(4), 295-305.

Thompson, D. A., Ali, R. R., Banin, E., Branham, K. E., Flannery, J. G., Gamm, D. M., ... Zacks, D. N. Monaciano Consortium. (2015). Advancing therapeutic strategies for inherited retinal degeneration: Recommendations from the Monaciano Symposium. Investigative Ophthalmology \& Visual Science, 56(2), 918-931.

Thompson, D. A., McHenry, C. L., Li, Y., Richards, J. E., Othman, M. I., Schwinger, E., ... Gal, A. (2002). Retinal dystrophy due to paternal isodisomy for chromosome 1 or chromosome 2, with homoallelism for mutations in RPE65 or MERTK, respectively. American Journal of Human Genetics, 70(1), 224-229.

Thorp, E., Vaisar, T., Subramanian, M., Mautner, L., Blobel, C., \& Tabas, I. (2011). Shedding of the Mer tyrosine kinase receptor is mediated by ADAM17 protein through a pathway involving reactive oxygen species, protein kinase Cdelta, and p38 mitogen-activated protein kinase (MAPK). Journal of Biological Chemistry, 286(38), 33335-33344.

Tschernutter, M., Jenkins, S. A., Waseem, N. H., Saihan, Z., Holder, G. E., Bird, A. C., ... Webster, A. R. (2006). Clinical characterisation of a family with retinal dystrophy caused by mutation in the Mertk gene. British Journal of Ophthalmology, 90(6), 718-723. 
Vollrath, D., Yasumura, D., Benchorin, G., Matthes, M. T., Feng, W., Nguyen, N. M., ... LaVail, M. M. (2015). Tyro3 modulates Mertk-associated retinal degeneration. Plos Genetics, 11(12), e1005723.

Wang, F., Wang, H., Tuan, H. F., Nguyen, D. H., Sun, V., Keser, V., ... Chen, R. (2014a). Next generation sequencing-based molecular diagnosis of retinitis pigmentosa: Identification of a novel genotype-phenotype correlation and clinical refinements. Human Genetics, 133(3), 331345.

Wang, J., Zhang, V. W., Feng, Y., Tian, X., Li, F. Y., Truong, C., ... Wong, L. J. (2014b). Dependable and efficient clinical utility of target capture-based deep sequencing in molecular diagnosis of retinitis pigmentosa. Investigative Ophthalmology \& Visual Science, 55(10), 62136223.

Weier, H. U., Fung, J., \& Lersch, R. A. (1999). Assignment of protooncogene MERTK (a.k.a. c-mer) to human chromosome $2 \mathrm{q} 14.1$ by in situ hybridization. Cytogenetics and Cell Genetics, 84(1-2), 91-92.

Wright, A. F., Chakarova, C. F., Abd El-Aziz, M. M., \& Bhattacharya, S. S. (2010). Photoreceptor degeneration: Genetic and mechanistic dissection of a complex trait. Nature Reviews Genetics, 11(4), 273-284.

Xu, Y., Guan, L., Shen, T., Zhang, J., Xiao, X., Jiang, H., ... Zhang, Q. (2014). Mutations of 60 known causative genes in 157 families with retini- tis pigmentosa based on exome sequencing. Human Genetics, 133(10), 1255-1271.

Yang, M., Li, S., Liu, W., Yang, Y., Zhang, L., Zhang, S., ... Zhu, X. (2018). Targeted next-generation sequencing reveals a novel frameshift mutation in the MERTK gene in a Chinese family with retinitis pigmentosa. Genetic Testing and Molecular Biomarkers, 22(3), 165-169.

Zarbin, M. (2016). Cell-based therapy for degenerative retinal disease. Trends in Molecular Medicine, 22(2), 115-134.

\section{SUPPORTING INFORMATION}

Additional Supporting Information may be found online in the supporting information tab for this article. 